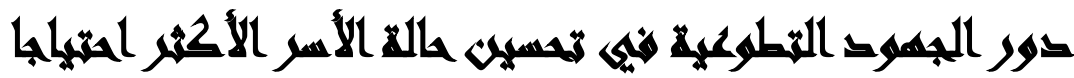

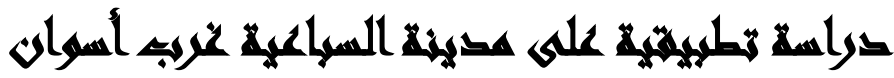

\section{[9]}

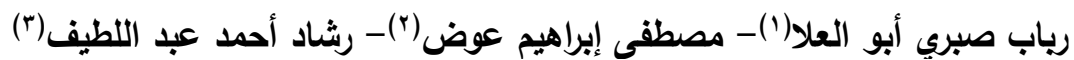

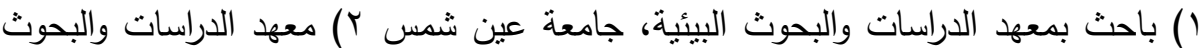

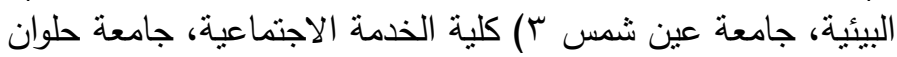

\section{المستخله}

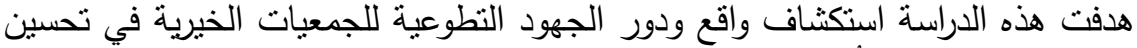
حالة الأسر الأكثر احتباجاُ كأبرز المشكلات التي تواجه العمل التهل التطوعي داخل المجتمعات

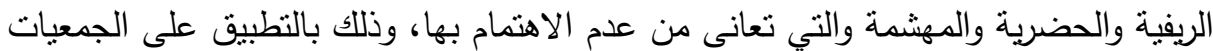

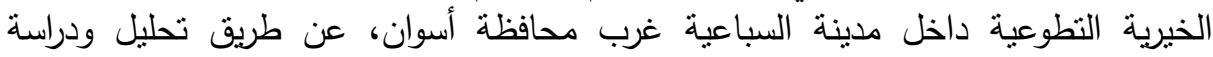

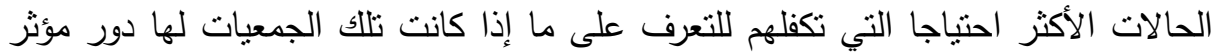
وفعال في تحسين معيشة تلك الأسر داخل المدينة، واستعراض المساعدات الكات الكات المادية والعينية

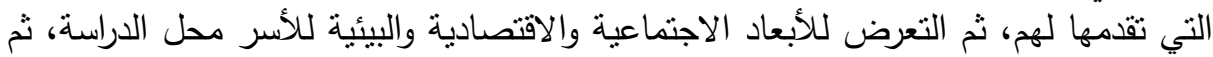

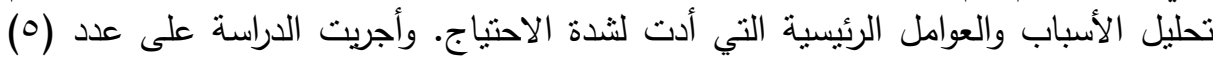

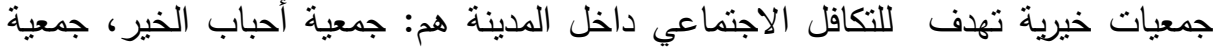

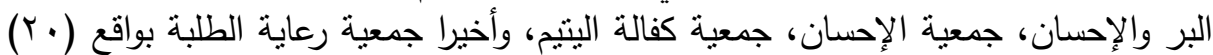

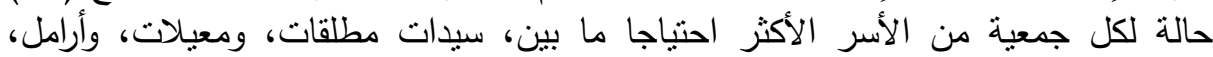

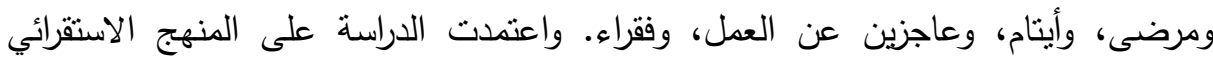
والاستتباطي والمنهج الوصفي التحليلي للوصول إلى أهدافها المحددة، وقد بُني هذا التهني المنهج

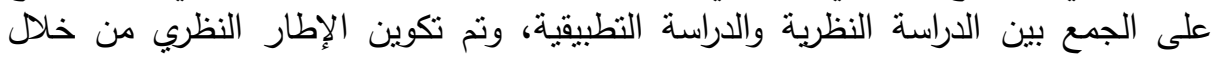

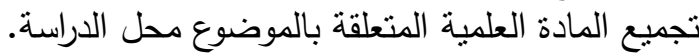

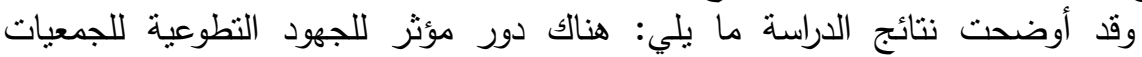

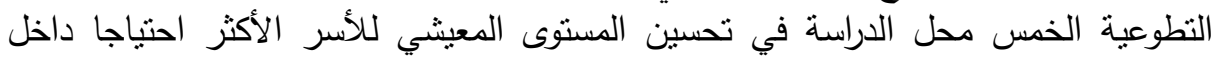

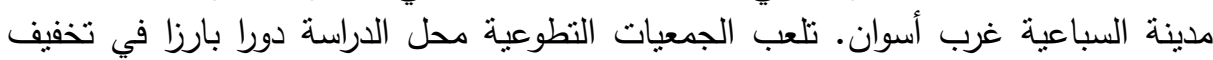

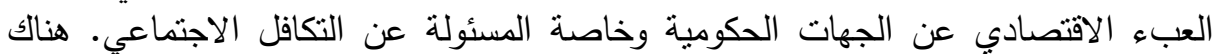

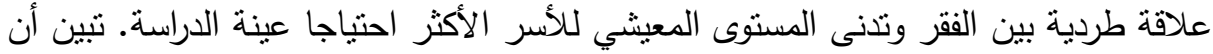

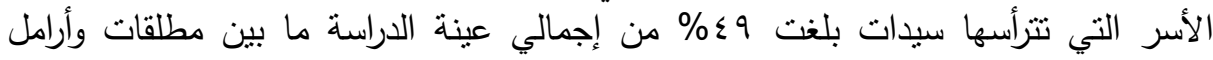

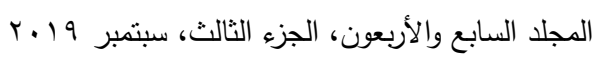


ومعيلات، بينما الأسر التي يترأسها رجال بلغت ابـ\%، وهو ما بعنى أن السيدات أكثر

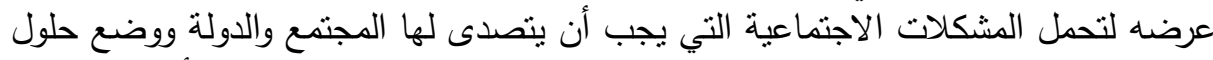

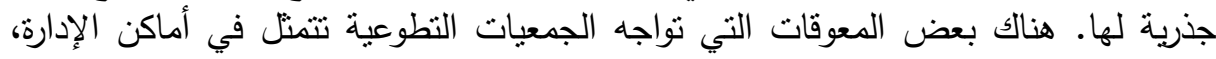
والبيروقراطية والروتين في القوانين المنظمة لإدارتها تؤثر على دورها المجتمعي تجاه خدمة التهات

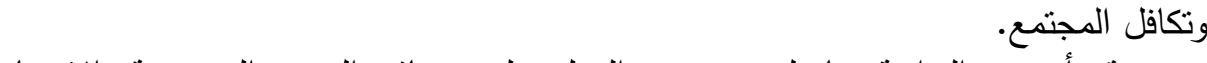

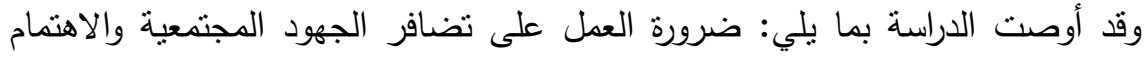

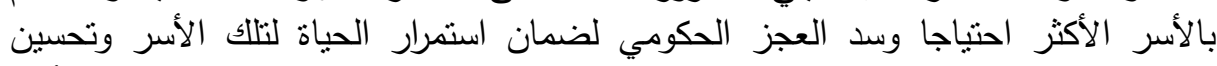

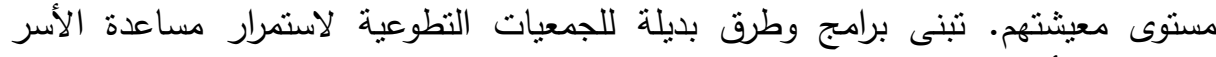

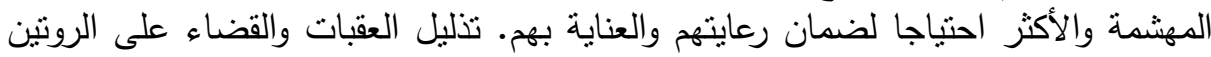

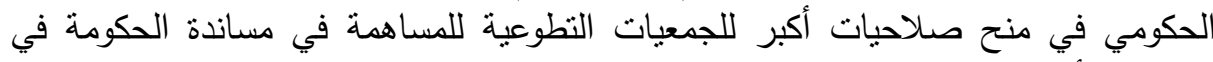
مساعدة الأسر غير القادرة على المعيشة.

\section{ranandl}

يمر العالم بأسره بالعديد من الأزمات والمشكلات الاجتماعية نظراً للظروف الاقتصادية والتحولات السياسية التي أثرت على بعض الأسر داخل المجتمعات الحضرية والريفية المختلفة

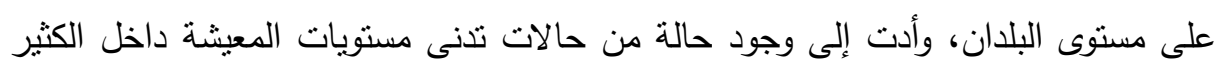

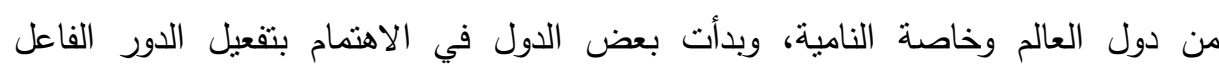

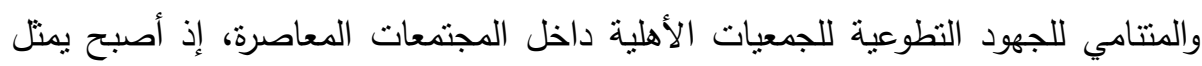

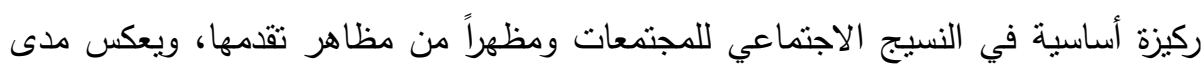
مساهمة أفراد المجتمع في بناء منظومة التكافل الاجتماعي بما يعزز جهود الدولة في التتمية.

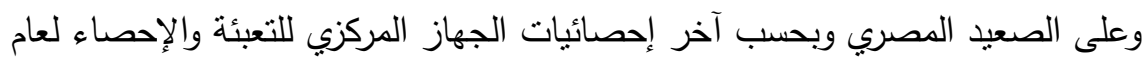
1 1. Y، التي أكدت ارتفاع نسب معدلات الفقر بسبب الكثير من المشكلات الاجتماعية لبعض الأسر أدى مما أدى لتدنى المستوى المعيشي والاقتصادي لهم. (الجهاز المركزي

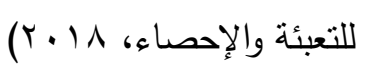

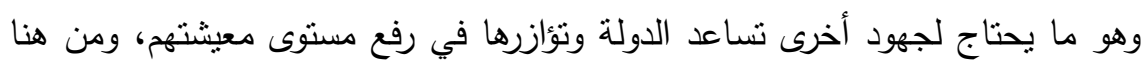
تأتى الدراسة لتلقى الضوء على أهمية ودور الجهود التطوعية التي تبذل داخل مدينة السباعية

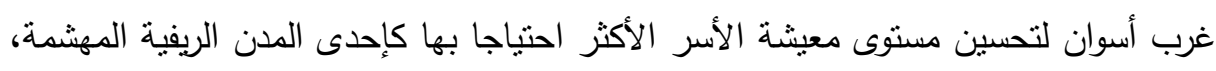

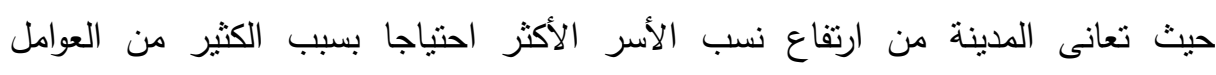


الاجتماعية التي من أهها، الفقر، والعوز المادي التي أدت لتنىى مستوى المعيشة وارتفاع نسب السيدات المعيلات والمطلقات.

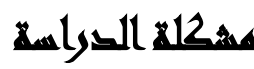

نظراً للظروف الاقتصادية والاجتماعية التي تعيشها مصر وازدياد حالات الطلاق وارتفاع

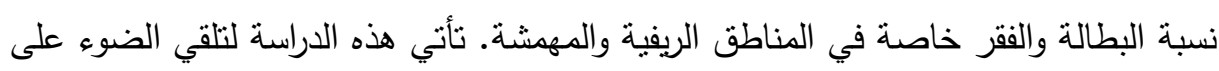

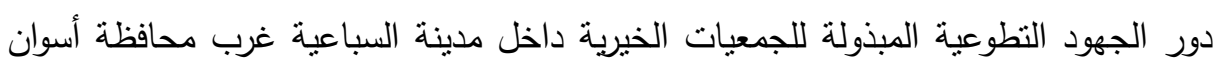
في تحسين حالة الأسر الأكثر احتياجا، حيث تعانى المدينة من كثرة الحالات الأسرية شديدة

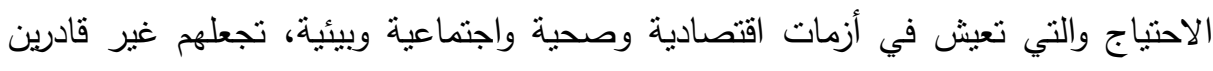

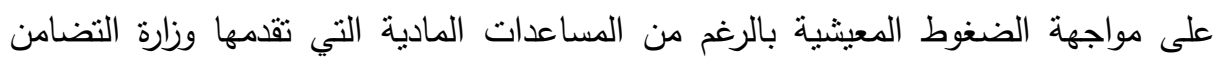

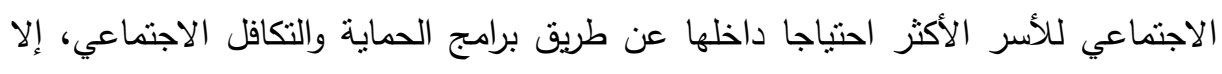

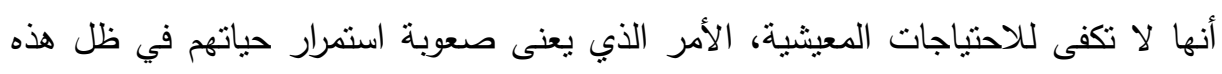

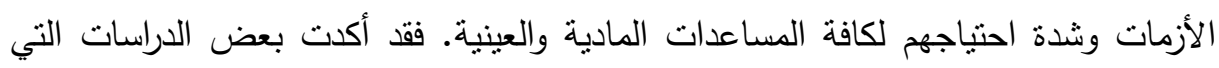

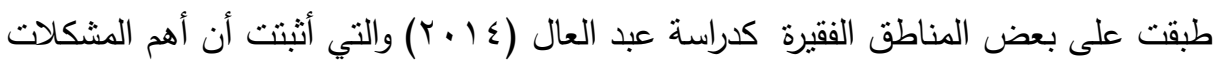

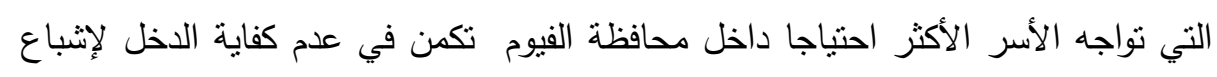
احتياجات الأسرة من الأكل والملبس وشراء الغذاء وغلاء الأسعار وقلة دخل الأسر، وأيضا

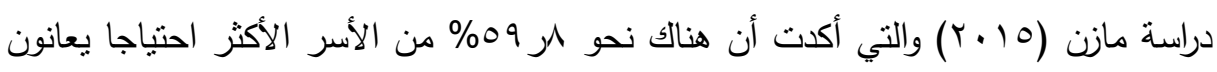

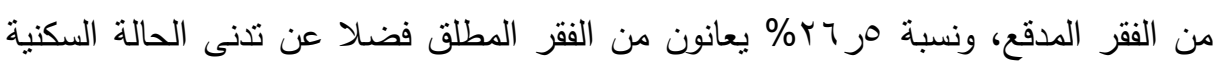

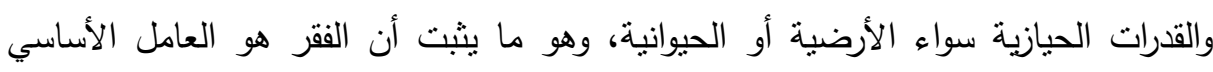
لمأسر الأكثر احتياجا.

ومن هنا يظهر الدور الاجتماعي للجهود التطوعية سواء الفردية أو الجماعية التي تقوم التئي

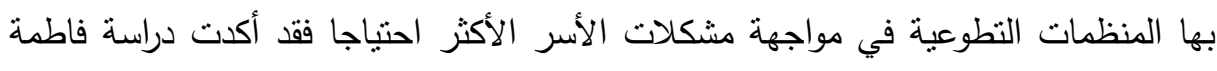
(Y. V V) 
المشكلات التي يعانون منها وتقديم أفضل الخدمات ومساعدتهم في توفير احتباجاتهم الحياتية، وكذلك الرفع من قدراتهم ومهاراتهم للاستفادة منها في تقدم المجتمع.

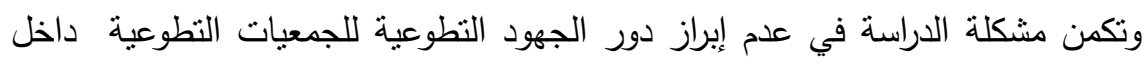
مدينة السباعية في تحسين حالة الأسر الأكثر احتياجا، بالرغم من الهتمام تلإنك الجمعيات بكفالة كافة الأسر الأكثر احتباجا داخلها عن طريق إمدادهم بالمساعدات المادية والعينية

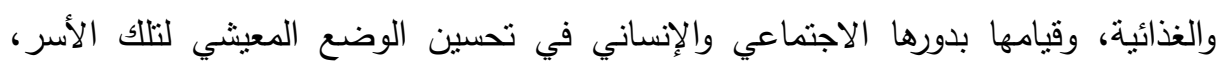
وتخفيف العبء الاقتصادي على الدولة ومساندتها في تحقيق البُعد الاجنماعي.

\section{تمساولايت التوراسما}

• ما هي طبيعة الجهود التطوعية المقدمة لمساعدة الأسر الأكثر احتياجاً؟

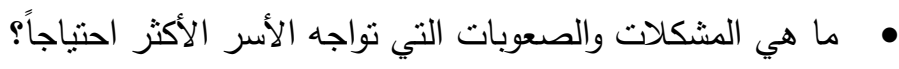

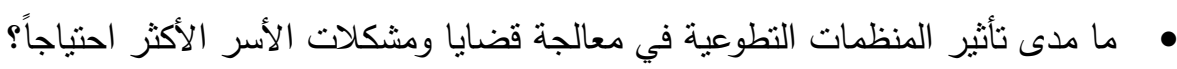

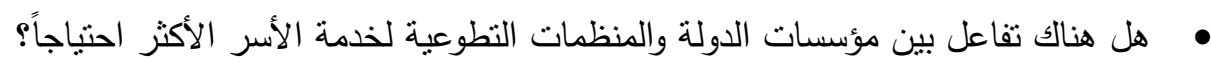
• هل هنالك معوقات وصعوبات تواجه جهود المنظمات التطوعية في مساندة ومساعدة

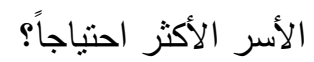

\section{الهساهيم التراسلة}

• التعرف على طبيعة الجهود التطوعية للمنظمات التطوعية في مساعدة الأسر الأكثر احتياجاً. دراسة مدى تأثير المنظمات النظوعية في معالجة قضايا ومشكلات الأسر الأكثر احتياجاً. • عليل طبيعة المشكلات والعوامل التي تواجه الأسر الفقيرة والأكثر احتباجاً. دراسة المعوقات والصعوبات التي نواجه جهود المنظمات النطوعية في مساندة ومساعدة الأسر الأكثر احتياجاً. تصنيف الفئات الأكثر احتياجا من حيث العوامل الاجتماعية التي أدت لذللك. 


\section{هضوض الصراسلة}

الحدود المكانية: تتحدد الحدود المكانية للاراسة الحالية في مدينة السباعية غرب محافظة

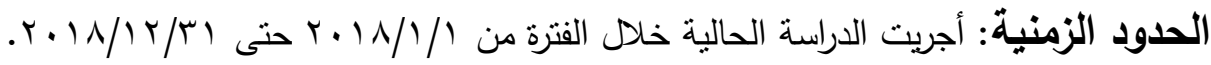
الحدود البشرية: أجريت الدراسة على عينة قوامها (...1) حالة من حالات الأسر الأكثر احتياجا يمنلون عدد (0) جمعيات تطوعية داخل المدينة.

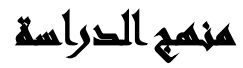

في سبيل تحقيق هدف البحث والرد على تساؤلاته، اعتمد الباحثّن في الدراسة التطبيقية

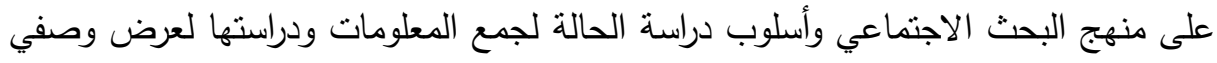
معمق واقعي لنموذج الحالة التي تتم دراستها، وذلك من خلال المقابلات الثخصية المتعقة لجمع المعلومات والبيانات اللازمة لإتمام الدراسة. أما مصدر البيانات فقد نم الحصول عليها من مصدرين هما: المصادر الثانوية: حيث اتجه الباحثون في معالجة الإطار النظري للاراسة إلى مصادر

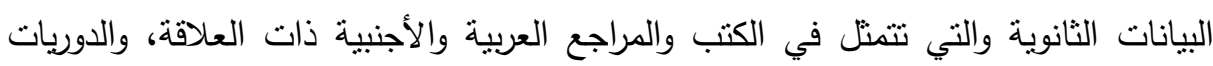
والمقالات والتقارير، والأبحاث والدراسات السابقة التي تناولت موضوع الدارسة، والبحث والمطالعة في مواقع الإنترنت المختلفة.

المصادر الأولية: وتتمتل في جمع البيانات الأولية ميدانياً، وذلك من خلال المقابلات الثخصية المتعمقة والملاحظة الثخصية، واستمارة دراسة الحالة التي تدرس الظاهرة وتحللها والتي تم تصميمها خصيصاً لهذا الغرض. 


\section{أهمبه التوراسة}

الأهمية العلمية: تكمن الأهمية العلمية للاراسة في أنها تتعرض إلى مشكلة من أهم

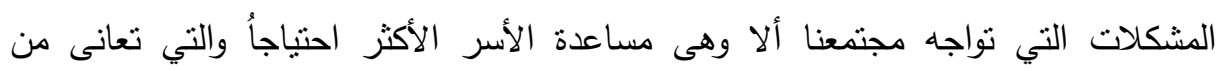
مشكلات اقتصادية واجتماعية وصحية تؤثر على استمرار حياتهم المعيشية.

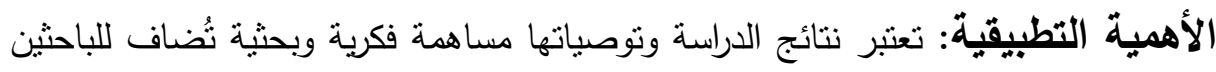

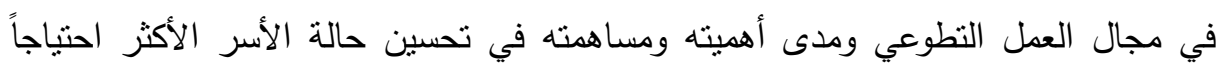

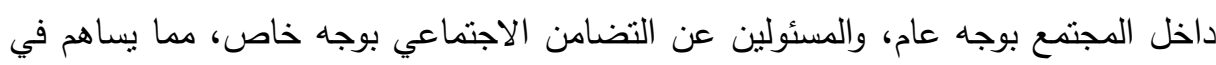
زيادة الاهتمام بتلك الأسر ورعايتهم ورقع مستوى معيشتهم.

\section{همبلحاهي القراسة}

مفهوم التطوع: هو ذلك الجها الذي يبذله الإنسان لمجتمعه بلا مقابل وبدافع منه يستهذف

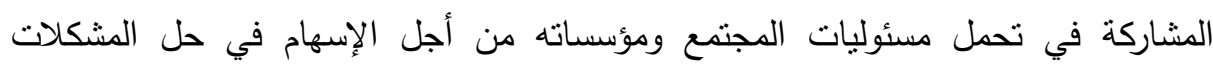

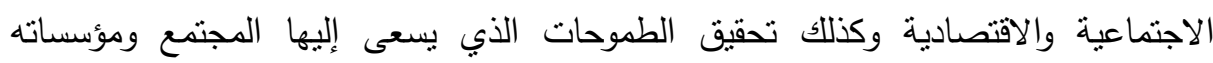

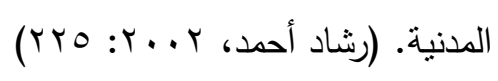
الجهود التطوعية: هي كافة الجهود الذي يبذلها الإنسان من أجل مجتمعه أو من أجل أجل

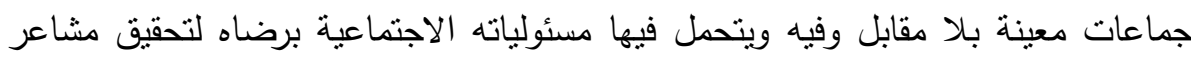

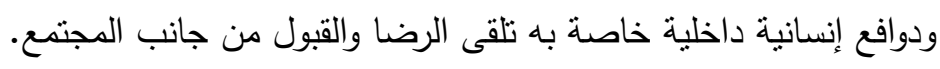

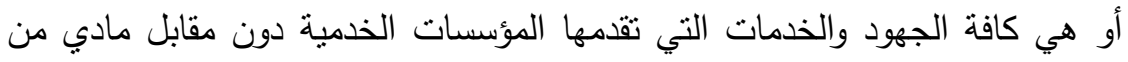

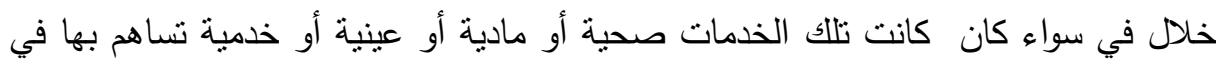

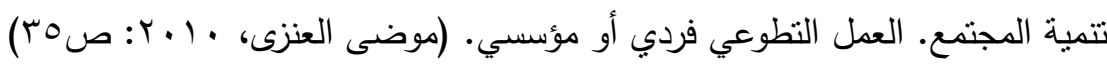

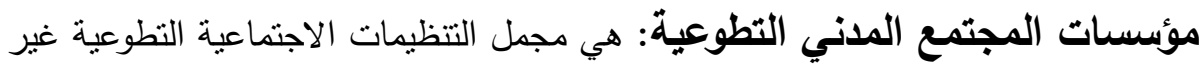
الحكومية وغير الإرثية والتي ترعى الفرد وتعظم من قدراته على المشاركة في الحياة العامة،

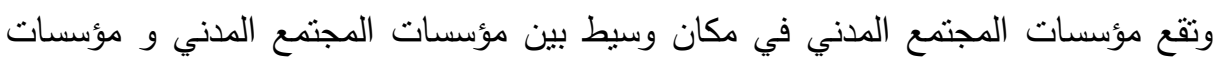

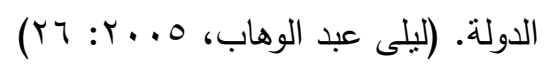


مفهوم الأسر الأكثر احتياجاً: هم صفة من الناس غير قادرين على إعالة أنفسهم على الإطلاق أو حتى الوصول إلى الحد الأدنى المتفق عليه بدون مساعدة خارجية وتنقى إعالة الهن

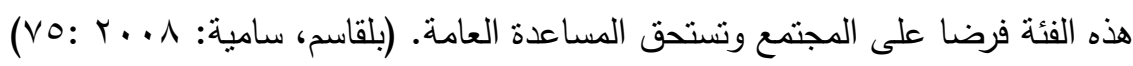

\section{الصراسايت الماريهات}

دراسة آمنة مثاعل (10 ( ب): نتاولت الدراسة العمل التطوعي وقيم المواطنة لاى الشباب السعودي- دراسة ميدانية مطبقة على عينة من المنطوعين في المملكة العربية

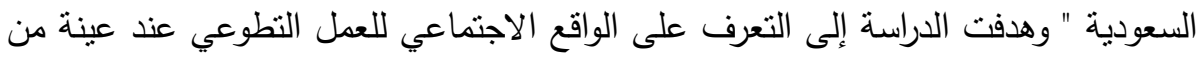
الثباب السعودي، ومعرفة أنواع المبادرات التطوعية التي شارك فيها المتطوعين. وأثثتت نتائج الدراسة أن الدافع الأول للنطوع هو الرغبة في تتمية الخبرات والثرات والمهارات

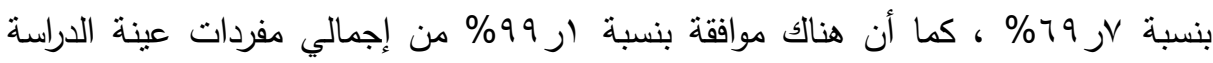
على أن العمل النطوعي يساهم في الانفتاح والتقبل وهو أحد أهم مبادئ المواطنة. دراسة دية حنين (10 ( †): نتاولت الدراسة دور المؤسسات الخيرية في التتمية الاجتماعية داخل المجتمع الجزائري. وهدفت الدراسة إلى التعرف على دور المؤسسات الخيرية في التتمية الاجتماعية، ومدى أهمية تتمية الإحساس بالمسؤولية لدى المشاركين في العمل التطوعي. وأثتبت نتائج الدراسة أن من أهم ما تقوم به المؤسسات الخيرية، كفالة اليتيم والسعي على الأرامل وعمارة المساجد وقضاء الديون وكفالة الطلبة. دراسة: (Chau \& others: 2015): تتاولت الدراسة العلاقة بين العمل التطوعي

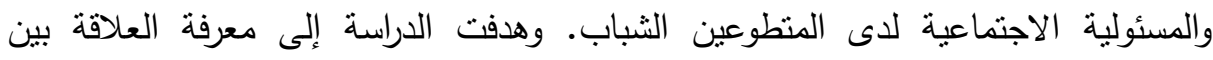
المسئولية الاجتماعية والنطوع، ومدى أهمية العمل التطوعي بالنسبة للثباب. 
وأثتتت نتائج الدراسة أن هناك تأثنر ايجابي للمسئولية الاجتماعية على المتطوعين الثباب بعد ستة أثهر من التطوع، كما أن هناك أهمية للعمل التطوعي في تحقيق التنمية التئية

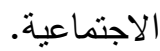

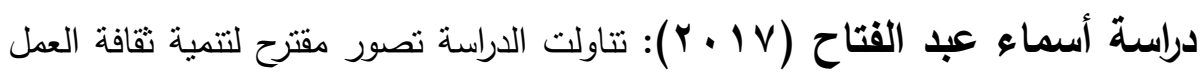

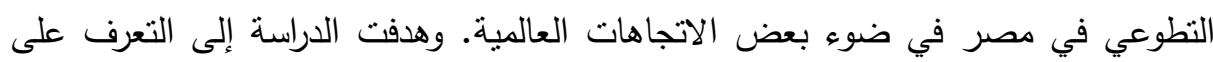

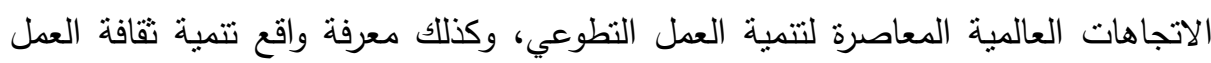

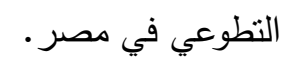

وأثنتت نتائج الدراسة أن هناك قصور عند بعض شرائح المجتمع للوعي والفهم الحقيقي

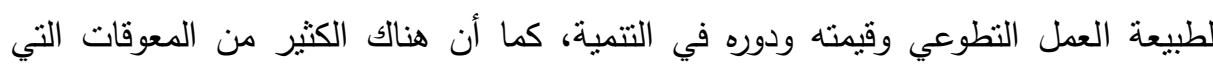
تعوق العمل التطوعي. دراسة (Sintya, et al: 2018$)$ (تناولت الدراسة تأثثير برنامج الأمل الأسرى التطوعي

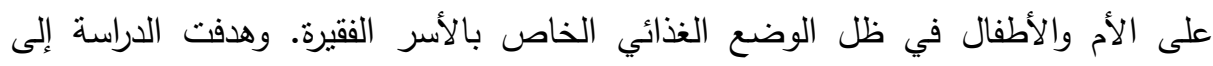
التعرف على دخل الأسرة وطرق دعم الأسرة الفقيرة. وأثنتت نتائج الدراسة أن أطفال الأسر الفقيرة أكثر عرضمة الأنه لأمراض عديدة مع سوء

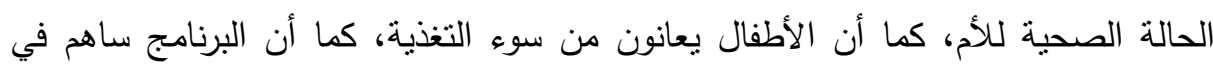

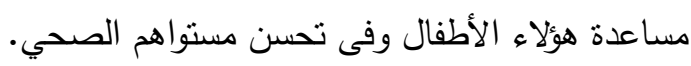

\section{الإجبراعاهي المنهمبه للقوراسة}

منهج الاراسة: استخدم الباحثون المنهج الوصفي التحليلي وقد بُني هذا المنهج على الجمع بين الدراسة النظرية والدراسة التطبيقية. حيث اعتمد الباحثون على إجراء دراسة تطبيقية لعينة مكونة من (· (1) أسرة من الأسر الأكثر احتباجا لعدد (0) جمعيات تطوعية، وتم تحليل

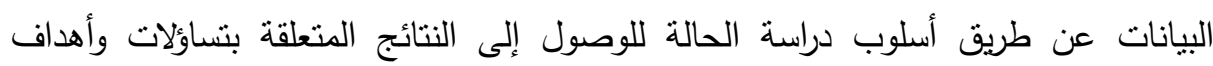


استمارة نموذج دراسة الحالة: هي نموذج يضم مجموعة من أسئلة توجه إلى الأفراد من أجل

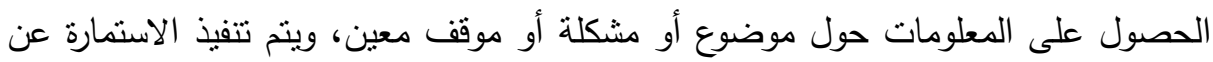
طريق المقابلة الثخصية والملاحظة الشخصية لحالات الدراسة. ويُعد النموذج الأداة الرئيسية التي اعتمدت غليها الباحثة في جمع البيانات الخاصة بالدراسة لأنها من أنسب الأدوات لجمع أكبر قدر من البيانات من أفراد العينة. مرحلة التأكد من صدق الاستمارة وثباتها:

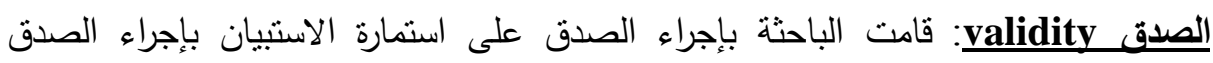
الظاهري على الاستمارة وذللك من خلال عرضها على عدد من المحكمين من أساتذة علم

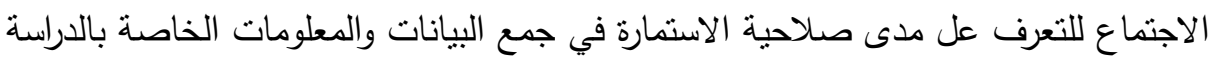
وقد ثم التعديل بعض العبارات وإعادة صياغة وحذف وإضافة البعض الآخر في ضوه ملاحظات السادة المحكمين.

الثبات Reliability: يشير مفهوم الثبات إلى اتساق أداة القياس، أو إمكانية الاعتماد عليها، وتكرار استخدامها في القياس أو بمعنى آخر حصول الباحثة على نفس النتائج إذا استخدمت أداة القياس أكثر من مرة. وهذا وقد احتوت الاستمارة على عدد من الأسئلة كل

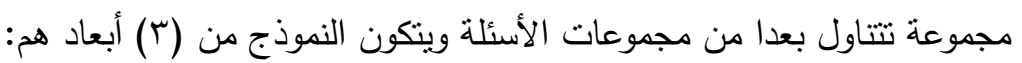

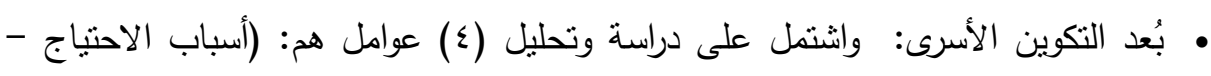
عوامل زيادة شدة الاحتياج - وسائل التعايش المادية - الإمكانيات المستقلبلية). • بُعد التكوين الاقتصادي: واثتمل على دراسة وتحليل (0) عوامل هم: (الدخل الثهري

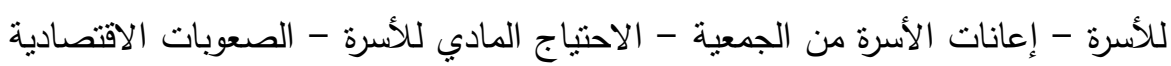
التي تواجه الأسرة - التأثير الاقتصادي للجمعية على معيشة الأسرة). • البُعد البيئي: وانتنمل على دراسة وتحليل (0) عوامل هم: (حالة السكن - نوع السكن -

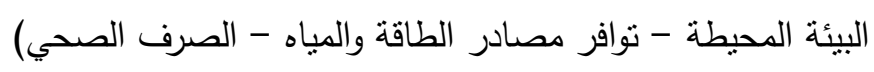


وقد تم دراسة وتحليل كل أسرة على حدا وتفريغ البيانات في صورة جداول تعبر عن حالة كل أسرة من خلال الأبعاد (الاجتماعية والاقتصادية والبيئية) التي تم تحديدها من خلانل نموذج دراسة الحالة. ثم تشخيص المشكلات التي تواجهها تلك الأسر وطبيعتها وتحديد أبعادها بشكل واقعي، وهو ما أدى للوصول إلى قيم تم ترجمتها في صورة بيانات وأرقام ونسب تُوني

$$
\text { مئوية وصولا لأهداف الدراسة. }
$$

وأجريت الدراسة على عينة قوامها ( . . (1) حالة من حالات الأسر الأكثر احتياجا يمثلون

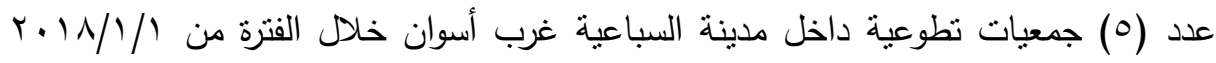

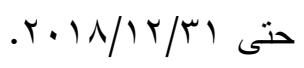

\section{الإطار اللنظليه للتدواسة}

التطوع: ينظر إلى النطوع بأنه ذلك النشاط الاجتماعي الذي يقوم به الأفراد المنطوعين داخل

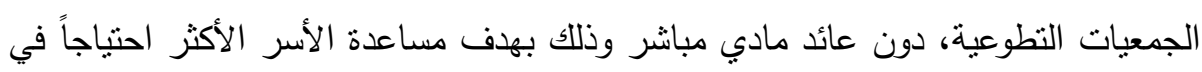

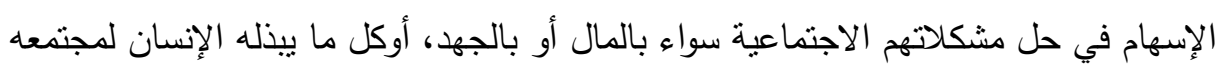

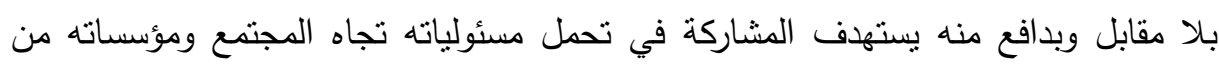

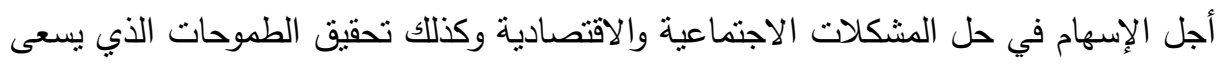

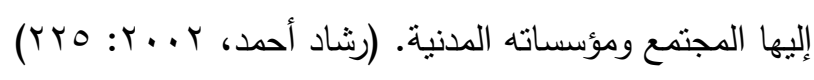
وتتمثل الجهود التطوعية في الآتي:

كافة الجهود التي يبذلها الإنسان من أجل مجتمعه أو من أجل جماعات معينة بلا مقابل.

تحمل مسئوليات العمل التطوعي من خلال المؤسسات الاجتماعية القائمة.

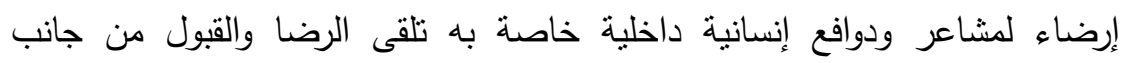

المجتمع.

مجهود قائم يبذله الفرد قائم على مهارة أو خبرة معينة عن رغبة واختباره بغرض تقديم واجب اجتماعي وإنساني دون النظر للحصول على مقابل. 


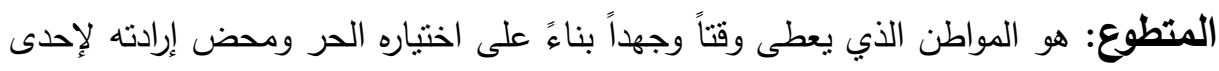

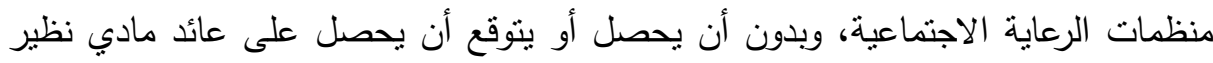

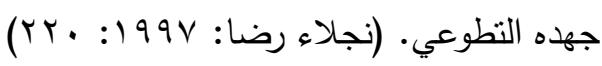
مؤسسات المجتمع المدني التطوعية: هي مجمل التظظيمات الاجتماعية التطوعية غير التهاء

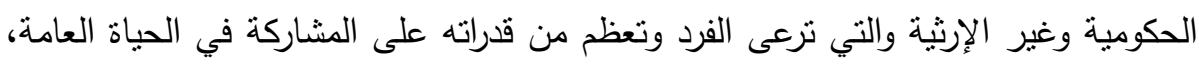
وتقع مؤسسات المجتمع المدني في مكان وسيط بين مؤسسات المجتمع المدني ومؤسسات

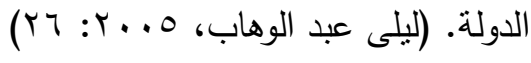

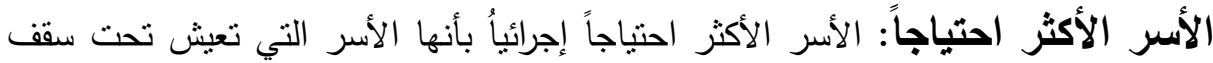

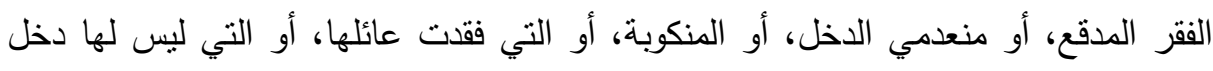

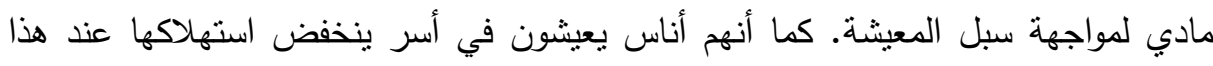

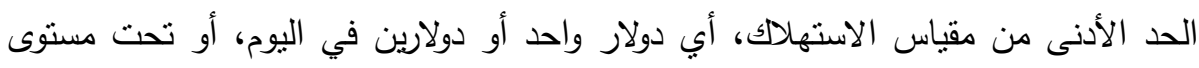

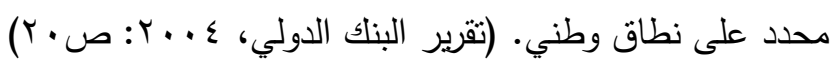

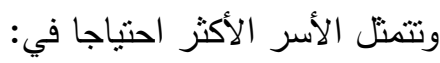
• الأسر الني ليس لهل دخل (منعدمي الدخل). • الأسر الني تقع تحت خط الفقر الدققع. • الأسر التي ترأسها امرأة معيلة أو أرملة أو مطلقة.

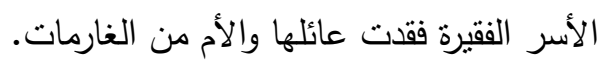

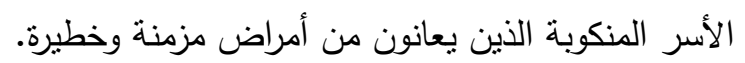
وترجع أسباب شدة الاحتياج لعدة أسباب منها:

أسباب اجتماعية: (نساء هجرهن أزواجهن ولا يعملون - المطلقات - المعيلات -

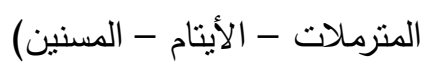
أسباب مادية: (عدم وجود دخل ثابت - عدم وجود مصدر ثابت للارزق - الفقر الددقع). 
أسباب صحية: (الأمراض المزمنة - عدم القدرة على العمل - تدنى المستوى البيئي تدنى المستوى المعيشي). تحليل حالة الأسر الأكثر احتياجا داخل المدينة محل الاراسة: وهو ما سوف يتتاوله الباحثون في موضوع الدراسة، حيث استخدموا نموذج دراسة الحالة أو المسح المجتمي، والذي يمثل الأسلوب والطريق إلى الواقعية الفعلية التي يستعين بها الباحثون

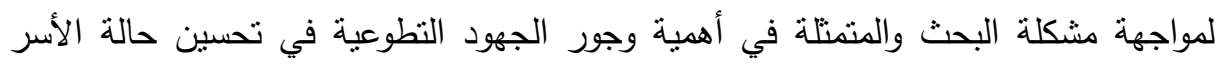

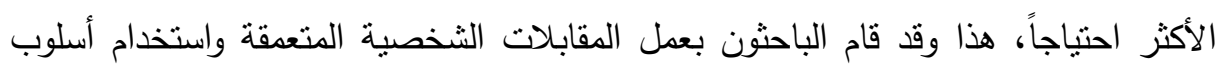

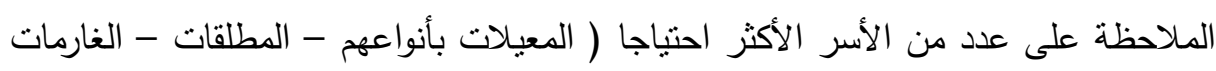

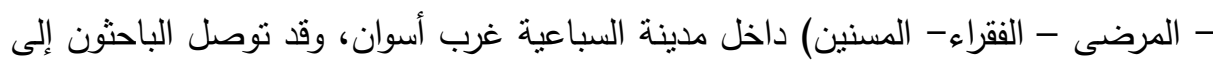
عدة نتائج منها: • هناك دور للجهود النطوعية في تحسين الأسر حالة الأسر الأكثر احتياجا داخل المدينة

$$
\text { بإمدادهم بالإعانات الثهرية والملابس والأدوية. }
$$

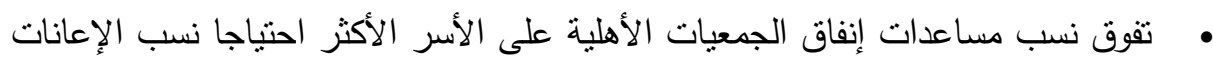
التحى تقدمها الحكومة من معاثشات تحت مسميات مختلفة • ععانى المدينة من ارتفاع نسبة الأسر الأكثر احتناجا ويأتي في مقدمنها الأسر الفقيرة

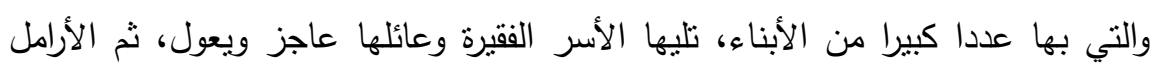

$$
\text { والمعيلات }
$$

ويرى الباحثون أنه نظرا لوجود علاقة بين الجهود التطوعية والأسر الأكثر احتباجا داخل

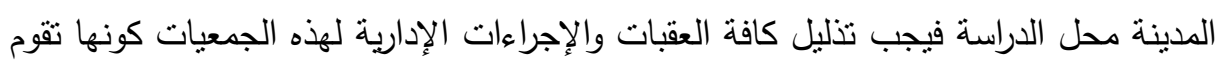
بدور اجتماعي يفوق الدور التي تقوم به الجهات الرسمية في هذا الثأن، حتى بتسنى القضاء على هذه الظاهرة أو تقليل نسب حدوثها وتعظيم المشاركة المجتمعية. كما نبرز هنا أهمية تضافر كافة المؤسسات المجتمعية والمدنية في المشاركة الإيجابية

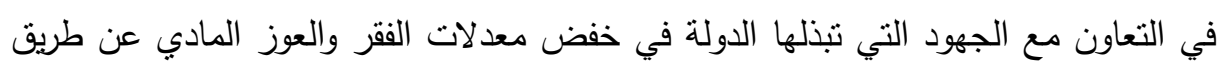
تبنى مشروعات خدمية وحث المجتمع على المشاركة الفعالة على كافة المستويات بتكفل 
مشروعات قومية في مجال الصحة والتعليم والعلاج وهى أكثر المجلات الخدمية التي يحتاجها المجتمع.

\section{نمأئ الترواسة}

وصف نتائج البيانات الأولية لعينة الدراسة:

النوع: يتبين أن فئة (فقير) يمتلون نسبة ^/٪ من إجمالي عينة الدراسة وهي أعلى نسبة في

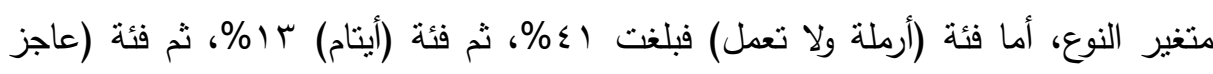

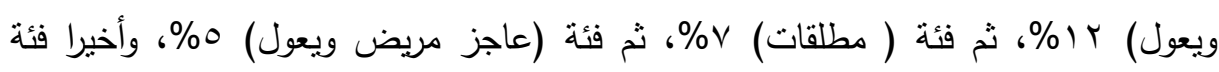

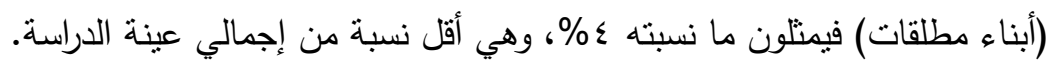

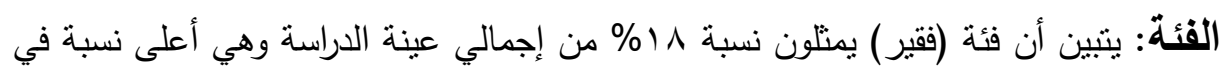

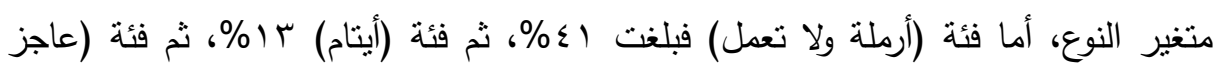

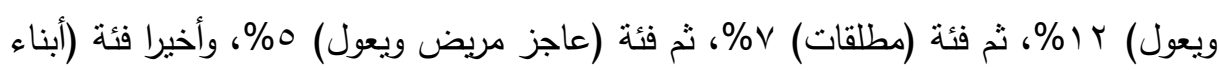
مطلقات) فيمتلون ما نسبته ؟ \% وهي أقل نسبة من إجمالي عينة الدراسة. المؤهل العلمي: يتبين أن عدد الذين يحملون مؤهل متوسط من فئة (الفقراء) ^ا حالة منهم

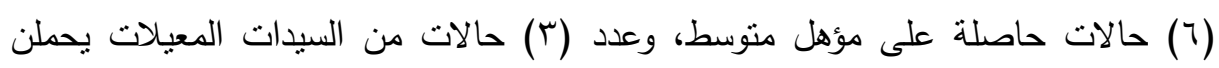

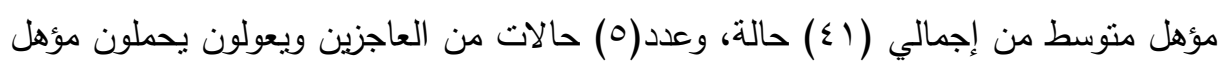

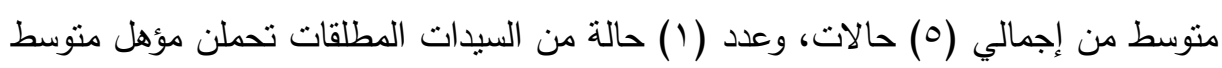

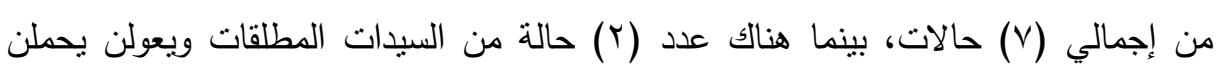

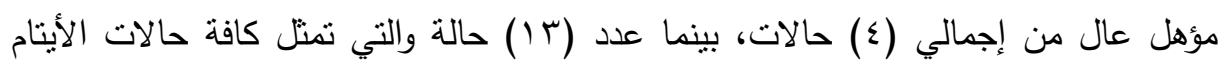
يدرسون بمراحل التعليم المختلفة. الوظيفة: يتبين أن نسبة VI V من إجمالي عينة الدراسة يعملون بأعمال موسمية متقطعة

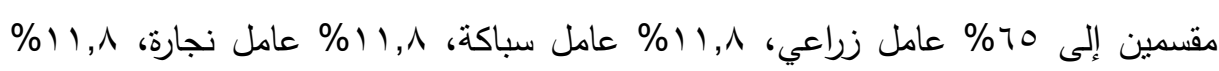


بائع خضار، أما باقي الفئات من إجمالي عينة الدراسة ككل والبالغ نسبتهم rی\% فهم لا بعملون. عرض وتحليل نتائج وأهداف وتساؤلات الاراسة: للوصول لأهداف ونتائج الدراسة قام الباحثون باستخدام أسلوب دراسة وتحليل الحالة المبنى على المقابلات والملاحظة الثخصية وتفريغ البيانات في صورة جداول للحصول على قيم رقمية وإحصائية كما هو موضح في ولئي الجدول التالي. جدول (1): يوضح قيم المساعدات المادية والعينية التي تقدمها الجمعيات التطوعية محل الدارسة

\begin{tabular}{|c|c|c|c|}
\hline نوع المساعدات المادية & قيمة المساعدات & الأسر الأكثر & اسم الجمعية \\
\hline سلع غذائية ـأدوات منزلية & 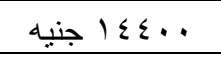 & r. & جمعية أحباب الخير \\
\hline سلع غذائية ـأدوات منزلية & . . . . . جنيه & $r$. & جمعية البر والإحسان \\
\hline سلع غذائية -أدوات منزلية & ا & $r$. & جمعية الإحسان \\
\hline سلع غذائية ـأدوات منزلية & . مبا النيه & $r$. & جمعية كفالة اليتيم \\
\hline سلع غذائية -أدوات منزلية & .090. & $r$. & جمعية رعاية الطلبة \\
\hline & . . & (... أسرة & الإجمالي \\
\hline
\end{tabular}

المصدر: (إعداد الباحثة) يتضح من الجدول السابق:

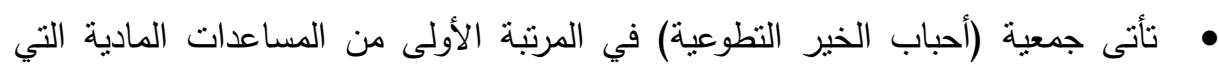

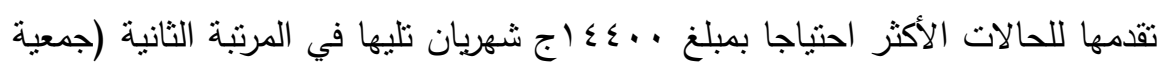

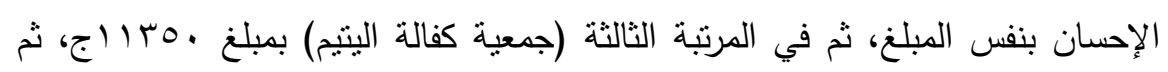

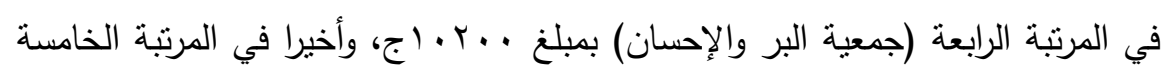

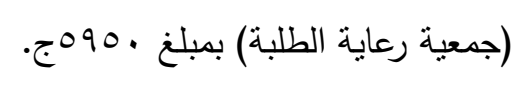

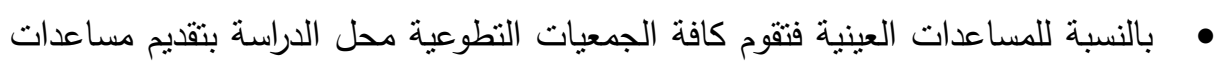
عينية للحالات الأكثر احتياجا بصفة دورية في صورة سلع غذائية وأدوات منزلية وأدوية علاجية. 
مجلة العلوم البيئية

معهد الدراسات والبحوث البيئة - جامعة عين شمس لئس

جدول (ץ): تحليل حالات الأسر الأكثر احتياجا التي تكفلها جمعية أحباب الخير

\begin{tabular}{|c|c|c|c|c|c|}
\hline البئُد & ومستلزمات المعيشة & الاقتصادي & البعُ الاجتماعي & الاحتباج & الحالة \\
\hline 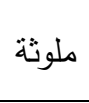 & غير مناسبة للمعيشة & تدهور الحالة & متوسط - عمالة & الفقر & 1 \\
\hline ملوثة ل & غير مناسبة للمعيشة & تدهور الحالة & بدون مؤهل - عمالة & الققر & r \\
\hline 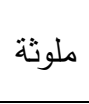 & غير مناسبة للمعيشة & تدهور الحالة & متوسط - عمالة & الفقر & r \\
\hline 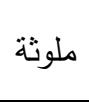 & غير مناسبة للمعيشة & تدهور الحالة & بدون عمل & الفقر & $\varepsilon$ \\
\hline 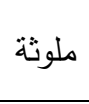 & غير مناسبة للمعيشة & تدهور الحالة & مؤهل متوسط - بدون & أرملة بلائ & 0 \\
\hline 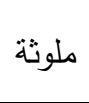 & مناسبة إلى حد ما & تدهور الحالة & مؤهل متوسط - بدون & أرملة معيلة & 7 \\
\hline 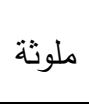 & غير مناسبة للمعيشة & تدهور الحالة & بدون مؤهل - بدون & أرملة بلائل & V \\
\hline 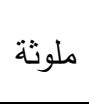 & غير مناسبة للمعيشة & تدهور الحالة & بدون مؤهل - بدون & أرملة - بلائل & $\wedge$ \\
\hline 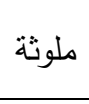 & غير مناسبة للمعيشة & تدهور الحالة & بدون مؤهل - بدون & بيتيم بلا & 9 \\
\hline 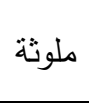 & غير مناسبة للمعيشة & تدهور الحالة & بدون مؤهل - بدون & يتيمة بلا & 1. \\
\hline ملوثة ل & غير مناسبة للمعيشة & تدهور الحالة & بدون مؤهل - بدون & عائل بتيمان بلا & 11 \\
\hline 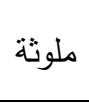 & غبر مناسبة للمعيشة & تدهور الحالة & بدون مؤهل - بدون & (ع) أيتام & Ir \\
\hline ملوثة ل & غير مناسبة للمعيشة & تدهور الحالة & بدون مؤهل - بدون & مطلقات & $1 \pi$ \\
\hline
\end{tabular}


رباب صبري أبو العلا وآخرون

تابع جدول (ץ): تحليل حالات الأسر الأكثر احتياجا التي تكفلها جمعية أحباب الخير

\begin{tabular}{|c|c|c|c|c|c|}
\hline البئيدي & ومستلزمات المعيشة السكن & الاقتصاديًا & البعُ الاجتماعي & سببب & الحالة \\
\hline ملوثة & غير مناسبة للمعيشة & تدهور الحالة & بدون مؤهل - بدون & مطلقات & $1 \varepsilon$ \\
\hline ملوثة & غير مناسبة للمعيشـة & تدهور الحالة & بدون مؤهل - بدون & مطلقة بلا & 10 \\
\hline ملوثة & غير مناسبة للمعيشـة & تلهور الحالة & بدون مؤهل - بدون & مطلقة تعول & 17 \\
\hline 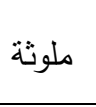 & غير مناسبة للمعيشـة & تدهور الحالة & بدون مؤهل - بدون & 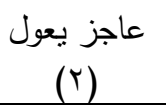 & iv \\
\hline ملوثة & غير مناسبة للمعيشـة & تدهور الحالة & بدون مؤهل - بدون & معيلة وتعول & 11 \\
\hline 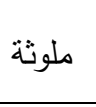 & غير مناسبة للمعيشة & تالاقتصادر الحالة & مؤهل متوسط - بدون & $\begin{array}{c}\text { معيلة تعول } \\
\text { (Y) }\end{array}$ & 19 \\
\hline ملوثة & غير مناسبة للمعيشة & تالاقور الحالة & بدون مؤهل - بدون & عاجز مسن & $r$. \\
\hline
\end{tabular}

المصدر : (إعداد الباحثة) من خلال نتائج وتحليل دراسة حالات المستقصى منهم الهيه

يتضح من تحليل الجدول السابق ما يلي:

- تهتم جمعية (أحباب الخير) بمساعدة الأسر الأكثر احتباجا حيث يبلغ عدد الحالات

الأكثر احتياجا (•r) حالة تم دراستها وتحليلها.

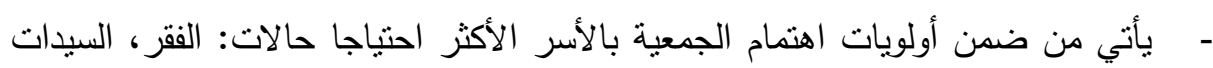

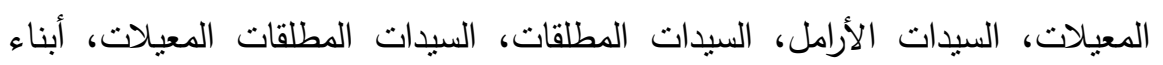

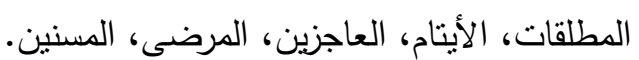

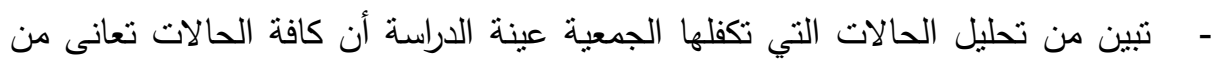

تدهور الحالة الاقتصادية بسبب عدم القدرة على الوفاء بالتزاماتهم لمواجهة منطلبات

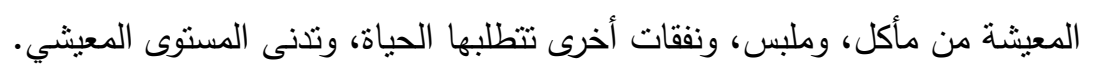
- البية الحالات التي تكفلها الجمعية بدون عمل ثابت ومستمر نظرا لظروفهم الاجتماعية

والجسدية التي تمنعهم من العمل كالمرضى، والمسنين، والعاجزين، والمعيلات المسنات.

192

المجلد السابع والأربعون، الجزء الثالث، سبتمبر 19 ـ ب 
- تعانى كافة الحالات الدراسية من سوء الوضع المعيشي والحالة السكنية ونقص المستلزمات والأدوات المعيشة التي لا تكفى للحياة المعيشية. - بالنسبة للوضع البيئي لا يوجد بالمدينة التي تعيش فيها كافة الحالات الدراسية التابعة

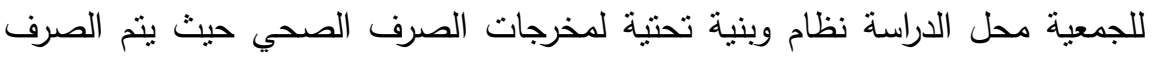
على بيارات بعمق ثلاثة أمتار يتم تفريغها من حين إلى حين، وهو ما يسبب زيادة في التلوث البيئي وسوء حالة التربة السكنية. جدول (ץ): تحليل حالات الأسر الأكثر احتياجا التي تكفلها جمعية البر والإحسان

\begin{tabular}{|c|c|c|c|c|c|}
\hline البيأبعد & حالة السكن ومستلزمات & البعً الاقتصادي & البعُد الاجتماعي & الاحتياج & الحالة \\
\hline ملوثة ل & غير مناسبة للمعيشة & تدهور الحالة & مؤهل موسمية - موسل & 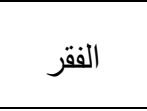 & 1 \\
\hline ملوثة & غير مناسبة للمعيشة & تدهور الحالة & بدالة موسمية & الفقر الفر & $r$ \\
\hline 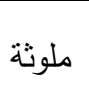 & غير مناسبة للمعيشة & تدهور الحالة & مؤهلة منوسط - عمسمية & الفقر & $r$ \\
\hline ملوثة ل & غير مناسبة للمعيشة & تدهور الحالة & بدون عمل & الفقر & $\varepsilon$ \\
\hline ملوثة ل & غير مناسبة للمعيشة & تدهور الحالة & مؤهل منوسط - & أرملة مسنة & $\circ$ \\
\hline ملوثة & مناسبة إلى حد ما & تدهور الحالة & مؤهل منوسط - & أرملة تعول & 7 \\
\hline ملوثة ل & غير مناسبة للمعيشة & تدهور الحالة & بدون مؤهل - بدون & أرملة مسنة & $v$ \\
\hline ملوثة ل & لا توجد كماليات & تدهور الحالة الاقتصادية & بدون مؤهل - بدون & عائل بلا & $\wedge$ \\
\hline ملوثة & مناسبة إلى حد ما & تدهور الحالة & بدون مؤهل - بدون عمل & يتيم بلا & 9 \\
\hline
\end{tabular}


رباب صبري أبو العلا وآخرون

تابع جدول (ץ): تحليل حالات الأسر الأكثر احتياجا التي تكفلها جمعية البر والإحسان

\begin{tabular}{|c|c|c|c|c|c|}
\hline البئئي & حالة السكن ومستلزمات & البعًا الاقتصادي & البعُد الاجتماعي & سببب الاحتباج & الحالة \\
\hline ملوثة & غير مناسبة للمعيشة & تدور الحالة & بدون مؤهل - بدون عمل & عائل & 1. \\
\hline ملوثة & غير مناسبة للمعيشة & تدور الحالة & بدون مؤهل - بدون عمل & يتيمان بلا & 11 \\
\hline ملوثة & غير مناسبة للمعيشة & تدهور الحالة & بدون مؤهل - بدون عمل & يتيم بلا & Ir \\
\hline ملوثة & غير مناسبة للمعيشة & تدهور الحالة & بدون مؤهل - بدون عمل & مطلقات & rו \\
\hline 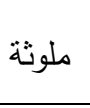 & غير مناسبة للمعيشة & تدهور الحالة & بدون مؤهل - بدون عمل & مطلقات & $1 \varepsilon$ \\
\hline 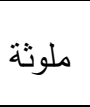 & غير مناسبة للمعيشة & تالاقور الحالة & بدون مؤهل - بدون عمل & الفقر & 10 \\
\hline 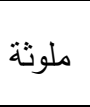 & غير مناسبة للمعيشة & تالاقور الحالة & بدون مؤهل - بدون عمل & وتعول (ع) مطة & 17 \\
\hline 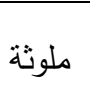 & غير مناسبة للمعيشة & تلاهور الحالة & بدون مؤهل - & 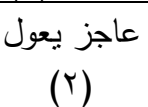 & iv \\
\hline ملوثة & مناسبة إلى حد ما & تلاهور الحالة & بدون مؤهل - بدون عمل & مسنة معيلة & 11 \\
\hline ملوثة & غير مناسبة للمعيشة & تدهور الحالة الاقتصادية & مؤهل منوسط- & امرأة تعول & 19 \\
\hline ملوثة & غير مناسبة للمعيشة & تدهور الحالة & بدون مؤهل - بدون عمل & 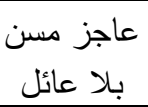 & $r$. \\
\hline
\end{tabular}

المصدر : إعداد الباحثة من خلال نتائج وتحليل دراسة حالات المستقصى منهم

يتضح من تحليل الجدول السابق ما يلي:

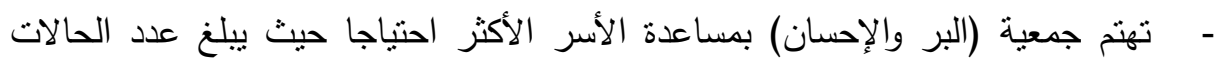

الأكثر احتياجا (·r) حالة تم دراستها وتحليلها. 
تهنم جمعية (البر والإحسان) بمساعدة الأسر الأكثر احتياجا حيث يأتي من ضمن

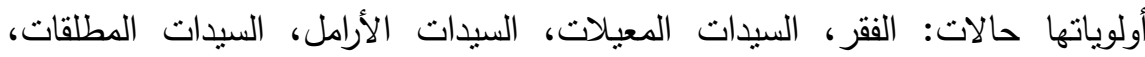

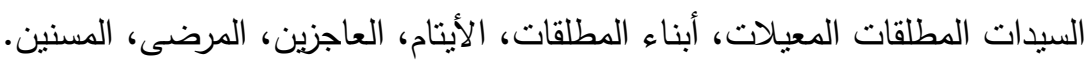

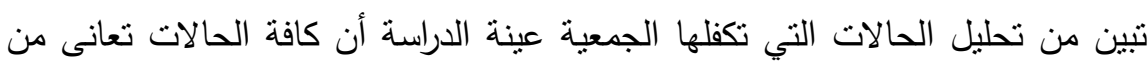
تدهور الحالة الاقتصادية بسبب عدم القدرة على الوفاء بالتزاماتهم لمواجهة منطلبات

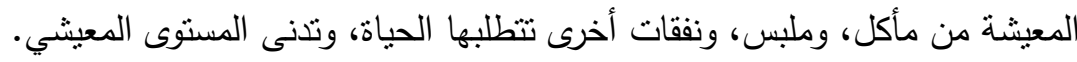
غالبية الحالات التي تكفلها الجمعية بدون عمل ثابت ومستمر نظرا لظروفهم الاجتماعية والجسدية التي تمنعهم من العمل كالمرضى، والمسنين، والعاجزين، والمعيلات المسنات.

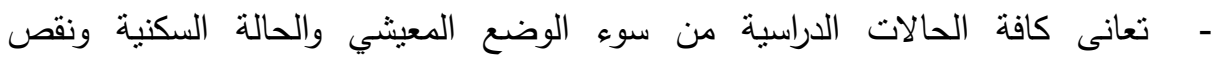
المستلزمات والأدوات المعيشة التي لا تكفى للحباة المعيشية. بالنسبة للوضع البيئي لا يوجد بالمدينة التي تعيش فيها كافة الحالات الدراسية التابعة

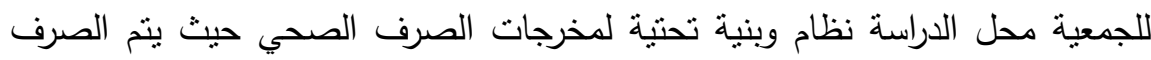
على بيارات بعمق ثلاثة أمتار يتم تقريغها من حين إلى حين، وهو ما يسبب زيادة في في لئ التلوث البيئي وسوء حالة التربة السكنية. 
رباب صبري أبو العلا وآخرون

جدول (ع): تحليل حالات الأسر الأكثر احتباجا التي تكفلها جمعية الإحسان

\begin{tabular}{|c|c|c|c|c|c|}
\hline البيئي & ومستلزمات المعيشة & البعًا الاقتصادي & البعُد الاجتماعي & سبب الاحتياج & الحالة \\
\hline 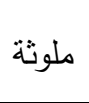 & غبر مناسبة للمعيشة & تدهور الحالة & بدون مؤهل - بدل & أرملة معيلة & 1 \\
\hline ملوثة & مناسبة إلى حد ما & تدهور الحالة & بدون مؤهل - بدون & أرملة تعول & r \\
\hline ملوثة & مناسبة إلى حد ما & تلاهور الحالة & مؤهل منوسط - & أرملة تعول & r \\
\hline 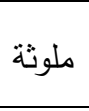 & غير مناسبة للمعيشة & تدهور الحالة & بدون مؤهل - بدون & أرملة تعول & $\varepsilon$ \\
\hline ملوثة ل & غير مناسبة للمعيشة & تدهور الحالة & بدون مؤهل - بدون عمل & أرملة تعول & 0 \\
\hline ملوثة & غير مناسبة للمعيشة & تدهور الحالة & بدون مؤهل - بدون & أرملة تعول & 7 \\
\hline ملوثة ل & غير مناسبة للمعيشة & تدهور الحالة الاقتصادية & بدون مؤهل - بدون عمل & أرملة نعول & v \\
\hline 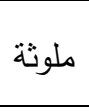 & لا لاجد كماليات & تدهور الحالة & مؤهل متوسط - & أرملة تعول & $\wedge$ \\
\hline ملوثة & مناسبة إلى حد ما & تدهور الحالة & بدون مؤهل - بدون & $\begin{array}{c}\text { أرملة تعول } \\
\text { (ץ) }\end{array}$ & 9 \\
\hline ملوثة & غير مناسبة للمعيشة & تدهور الحالة & بدون مؤهل - بدون & أرملة تعول & 1. \\
\hline ملوثة & غير مناسبة للمعيشة & تلاقتور الحالة & مؤهل متوسط - & 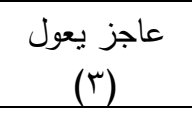 & 11 \\
\hline ملوثة & غير مناسبة للمعيشة & تدهور الحالة & بدون مؤهل - بدون & 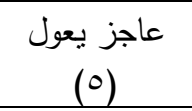 & IT \\
\hline ملوثة & غير مناسبة للمعيشة & تدهور الحالة & مؤهل متوسط - & 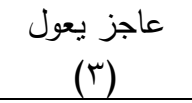 & 14 \\
\hline ملوثة ل & مناسبة إلى حد ما & تالاقتصادية الحالة & بدون مؤهل - & عاجز مسن زولثه & $1 \varepsilon$ \\
\hline
\end{tabular}


مجلة العلوم البيئية

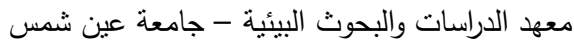

تابع جدول (ع): تحليل حالات الأسر الأكثر احتباجا التي تكفلها جمعية الإحسان

\begin{tabular}{|c|c|c|c|c|c|}
\hline البيئي & ومستلزمات المعيثة & البعًا الاقتصادي & البعُد الاجتماعي & سبب الاحتياج & الحالة \\
\hline ملوثة & مناسبة إلى حد ما & تدهور الحالة & بدون مؤهل - & 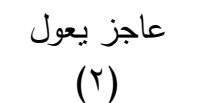 & 10 \\
\hline ملوثة & غير مناسبة للمعيشة & تدهور الحالة & بدون مؤهل - بدل & 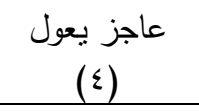 & 17 \\
\hline ملوثة & غير مناسبة للمعيشة & تالاقتصادر الحالة & بدون مؤهل - بدل & عاجز مسن زولن & IV \\
\hline ملوثة & غير مناسبة للمعيشة & تدهور الحالة & بدون مؤهل - عمية & فقير مريض (ع) & 11 \\
\hline ملوثة ل & غير مناسبة للمعيشة & تدهور الحالة & مؤهل منوسطية - عمالة موسمية & فقير يعول (0) & 19 \\
\hline ملوثة ل & غير مناسبة للمعيشة & تدهور الحالة & بدون مؤهل - بدون & فقير يعول (Y) & r. \\
\hline
\end{tabular}

المصدر : (إعداد الباحثة) من خلال نتائج وتحليل دراسة حالات المستقصى منهم

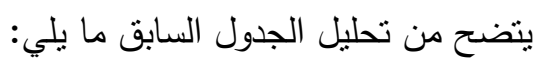

- تهتم جمعية (الإحسان) بمساعدة الأسر الأكثر احتياجا حيث يبلغ عدد الحالات الأكثر

$$
\text { احتياجا (· r) حالة نم دراستها وتحليلها. }
$$

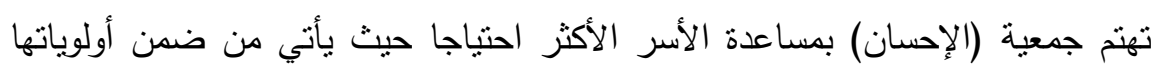

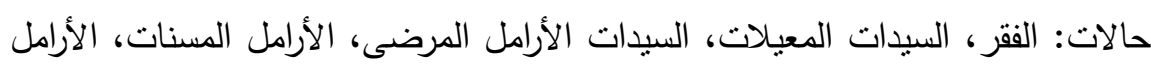

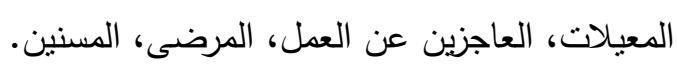

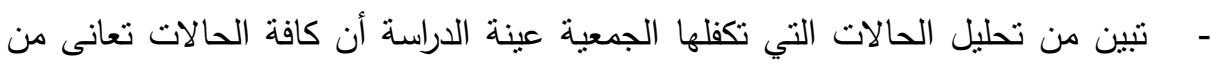
تدهور الحالة الاقتصادية بسبب عدم القدرة على الوفاء بالتزاماتهم لمواجهة منطلبات

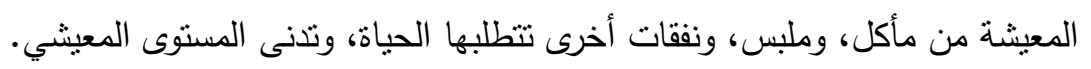


- البية الحالات التي تكفلها الجمعية بدون عمل ثابت ومستمر نظرا لظروفهم الاجتماعية والجسدية التي تمنعهم من العمل كالمرضى، والمسنين، والعاجزين، والمعيلات المسنات.

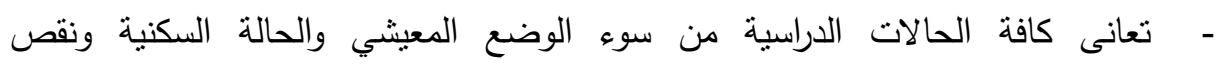
المستلزمات والأدوات المعيثة التي لا تكفى للحياة المعيشية.

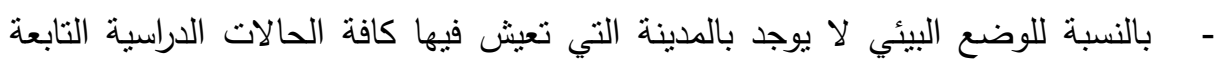

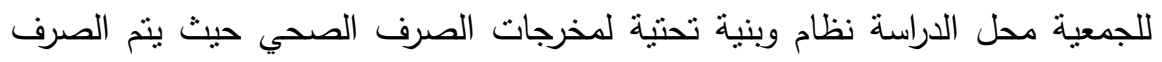
على بيارات بعمق ثلاثة أمتار يتم تفريغها من حين إلى حين، وهو مانه ما يسبب زيادة في لهي التلوث البيئي وسوء حالة التربة السكنية. جدول (•): تحليل حالات الأسر الأكثر احتياجا التي تكفلها جمعية كفالة اليتيم

\begin{tabular}{|c|c|c|c|c|c|}
\hline البيئي البُد & ومستلزمات المعيشة & البعًا الاقتصادي & البعُد الاجتماعي & سبب الاحتياج & الحالة \\
\hline ملوثة ل & غير مناسبة للمعيشة & تدهور الحالة & بدون عمل - عمسية & فقير يعول (r) & 1 \\
\hline 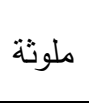 & لا تكفى مطلقا & تدهور الحالة & بدون مؤهل - عمية & فقير يعول (T) & r \\
\hline ملوثة ل & مناسبة إلى حد ما & تدهور الحالة & بدون مؤهل - بدل & $\begin{array}{c}\text { عاجز يعول } \\
\text { (Y) }\end{array}$ & r \\
\hline ملوثة ل & غير مناسبة للمعيشة & تدالاقتصادية الحالة & بدون مؤهل - بدون & مطلقة تعول & $\varepsilon$ \\
\hline ملوثة ل & غير مناسبة للمعيشة & تدهور الحالة & بدون مؤهل - بدون & يعول زوجته & 0 \\
\hline ملوثة & غير مناسبة للمعيشة & تدهور الحالة & مؤهل متوسط - & مطلقة بلائل & 7 \\
\hline ملوثة ل & غير مناسبة للمعيشة & تدهور الحالة & بدون مؤهل - بدون & مطلقة مريضة & $\checkmark$ \\
\hline ملوثة & غير مناسبة للمعيشة & تدهور الحالة & مؤهل متوسط - & مطلقة تعول & $\wedge$ \\
\hline ملوثة & مناسبة إلى حد ما & تدهور الحالة & بدون مؤهل - بدون & 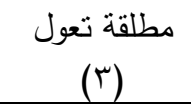 & 9 \\
\hline
\end{tabular}


مجلة العلوم البيئية

معهد الدراسات والبحوث البيئية - جامعة عين شمس لهس

تابع جدول (•): تحليل حالات الأسر الأكثر احتياجا التي تكفلها جمعية كفالة اليتيم

\begin{tabular}{|c|c|c|c|c|c|}
\hline البئيد & ومستلزمات المعيشة & البعً الاقتصادي & البعُد الاجتماعي & سبب الاحتياج & الحالة الة \\
\hline ملوثة ل & غير مناسبة للمعيشة & تدهور الحالة & بدون مؤهل - بدو & $\begin{array}{c}\text { أرملة تعول } \\
\text { (0) }\end{array}$ & 1. \\
\hline ملوثة ل & غير مناسبة للمعيشة & تدهور الحالة & بدون مؤهل - بدول & أرملة تعول & 11 \\
\hline ملوثة & غير مناسبة للمعيشة & تلاهور الحالة & بدون مؤهل - بدون & أرملة مريضة & ir \\
\hline ملوثة & غير مناسبة للمعيشة & تدهور الحالة & بدون مؤهل - بدون & أرملة مريضة & $1 \pi$ \\
\hline ملوثة & غير مناسبة للمعيشة & تلاهور الحالة & بدون مؤهل - بدون عمل & أرملة مسنة بلا & $1 \varepsilon$ \\
\hline ملوثة & غير مناسبة للمعيثة & تدهور الحالة & بدون مؤهل - بدون & أرملة مسنة بلا & 10 \\
\hline ملوثة & غير مناسبة للمعيشة & تدهور الحالة & بدون مؤهل - بدون عمل & أرملة مسنة بلا & 17 \\
\hline ملوثة ل & غير مناسبة للمعيشة & تدهور الحالة & بدون مؤهل - بدون عمل & أرملة وحيدة & iv \\
\hline ملوثة ل & غير مناسبة للمعيشة & تدهور الحالة & بدون مؤهل - بدون & يتيمان بلا & 11 \\
\hline 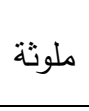 & غير مناسبة للمعيشة & تلاهور الحالة & بدون مؤهل - بدون عمل & (r) أيتام بلائل & 19 \\
\hline ملوثة ل & غير مناسبة للمعيشة & تلاهور الحالة & بدون مؤهل - بدون عمل & يتيم بلا عائل & $r$. \\
\hline
\end{tabular}

المصدر : (إعداد الباحثة) من خلال نتائج وتحليل دراسة حالات المستقصى منهم

يتضح من تحليل الجدول السابق ما يلي:

- تهتم جمعية (كفالة اليتيم) بمساعدة الأسر الأكثر احتباجا حيث يبلغ عدد الحالات الأكثر

$$
\text { احتياجا (·r) حالة تم دراستها وتحليلها. }
$$

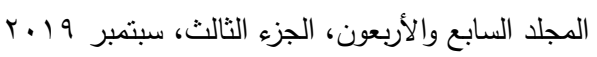


- تهتم جمعية (كفالة اليتيم) بمساعدة الأسر الأكثر احتياجا حيث يأتي من ضمن أولوياتها

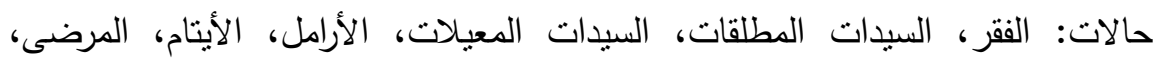

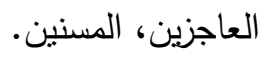
- - تبين من تحليل الحالات التي تكفلها الجمعية عينة الدراسة أن كافة الحالات نعانى من

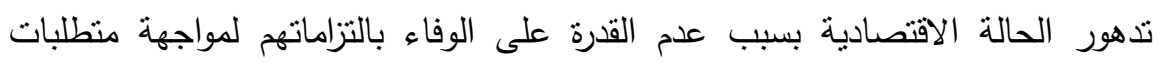

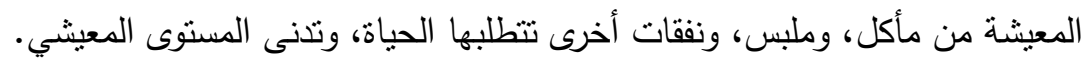
- البية الحالات التي تكفلها الجمعية بدون عمل ثابت ومستمر نظرا لظروفهم الاجتماعية والجسدية التي تمنعهم من العمل كالمرضى، والمسنين، والعاجزين، والمعيلات المسنات.

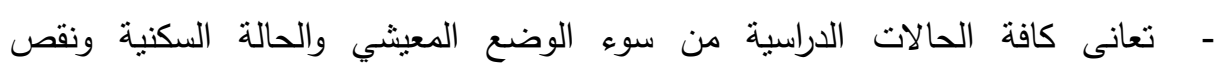
المستلزمات والأدوات المعيشة التي لا تكفى للحياة المعيشية.

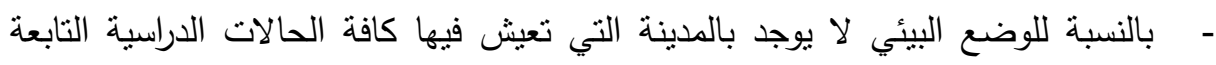

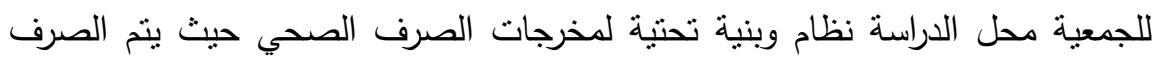

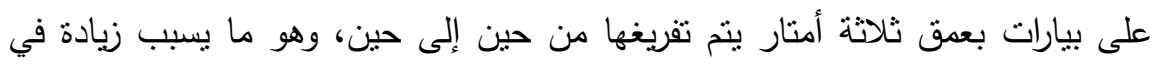
التلوث البيئي وسوء حالة التربة السكنية. 
مجلة العلوم البيئية

معهد الدراسات والبحوث البيئية - جامعة عين شمس لئ

جدول (†): تحليل حالات الأسر الأكثر احتياجا التي تكفلها جمعية رعاية الطلبة

\begin{tabular}{|c|c|c|c|c|c|}
\hline البيائي & ومستلزمات المعيشة & البعًا الاقتصادي & البعُد الاجتماعي & سبب الاحتياج & الحالة \\
\hline 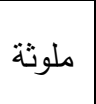 & غير مناسبة للمعيشة & تدهور الحالة & بدون مؤهل - عمالة موسمية & فقير يعول (r) & 1 \\
\hline 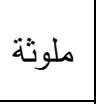 & غير مناسبة للمعيشة & تلاهور الحالة & عمالة موسمية & فقير يعول (r) & r \\
\hline 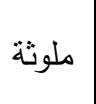 & غير مناسبة للمعيشة & تالهور الحالة & بدون مؤهل - عمالة موسية & فقير يعول (ع) & $r$ \\
\hline ملوثة ملة & غير مناسبة للمعيشة & تاهور الحالة & بدون مؤهل - عمالة موسية & فقير يعول (r) & $\varepsilon$ \\
\hline ملوثة & غير مناسبة للمعيشة & تدهور الحالة & بدون مؤهل - بدون عمل & أرملة مسنة & 0 \\
\hline ملوثة & غير مناسبة للمعيشة & تدهور الحالة & بدون مؤهل - بدل & أرملة تعول بنت & 7 \\
\hline 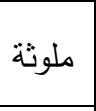 & غير مناسبة للمعيشة & تدهور الحالة & بدون مؤهل - بدون & أرملة تعول (r) & v \\
\hline ملوثة ملة & غير مناسبة للمعيشة & تدهور الحالة & بدون مؤهل - بدون عمل & مريضة بلا عائل & $\wedge$ \\
\hline 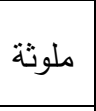 & غير مناسبة للمعيشة & تدهور الحالة & بدون مؤهل - بدون & مطلقة تعول (r) & 9 \\
\hline ملوثة & غير مناسبة للمعيشة & تدهور الحالة & بدون مؤهل - بدون & مطلقة وحيدة & 1. \\
\hline ملوثة ل & غير مناسبة للمعيشة & تدهور الحالة & مؤهل عالي - & مطلقة وحيدة & 11 \\
\hline ملوثة ملة & مناسبة إلى حد ما & تلاهور الحالة & مؤهل عالي - ملث & مطلقة وحيدة & Kr \\
\hline
\end{tabular}


رباب صبري أبو العلا وآخرون

تابع جدول (†): تحليل حالات الأسر الأكثر احتياجا التي تكفلها جمعية رعاية الطلبة

\begin{tabular}{|c|c|c|c|c|c|}
\hline البيئي البُعد & ومستلزمات المعيثة & البعًد الاقتصادي & البعُ الاجتماعي & سبب الاحتياج & الحالة \\
\hline ملوثة & مناسبة إلى حد ما & تدهور الحالة & بدون مؤهل - بدون & مطلقة وحيدة بلا & r \\
\hline ملوثة & مناسبة إلى حد ما & تدهور الحالة & بدون مؤهل - بدون & مسن في مرحلة & $1 \varepsilon$ \\
\hline ملوثة & مناسبة إلى حد ما & تدهور الحالة & بدون مؤهل - بدون & مسنة في مرحلة & 10 \\
\hline ملوثة & مناسبة إلى حد ما & تدهور الحالة & بدون مؤهل - بدون & يتيمتان بلا عائل & 17 \\
\hline ملوثة & غير مناسبة للمعيشة & تدهور الحالة & مؤهل متوسط - & يتيمة بلا عائل & IV \\
\hline ملوثة & غير مناسبة للمعيشة & تلالهور الحالة & مؤهل منوسط - & عاجز يعول (Y) & 11 \\
\hline ملوثة & غير مناسبة للمعيشة & تلالاقتصادية الحالة & مؤهل متوسط - & عاجز يعول زوجته & 19 \\
\hline ملوثة ل & غير مناسبة للمعيشة & تدهور الحالة & مؤهل متوسط - & عاجز يعول (Y) & $r$. \\
\hline
\end{tabular}

المصدر : (إعداد الباحثة) من خلال نتائج وتحليل دراسة حالات المستقصى منهم يتضح من تحليل الجدول السابق ما يلي:

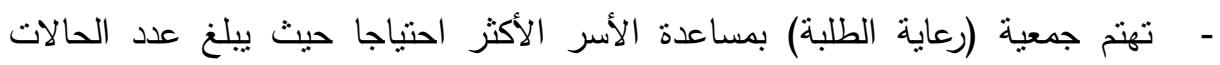
الأكثر احتياجا (·r) حالة تم دراستها وتحليلها.

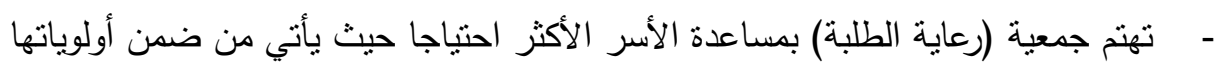

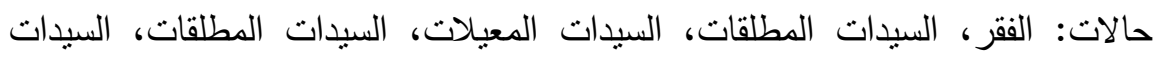
الأرامل، الأيتام، ، المرضى، العاجزين، المسنين، حالات الثيخوخة.

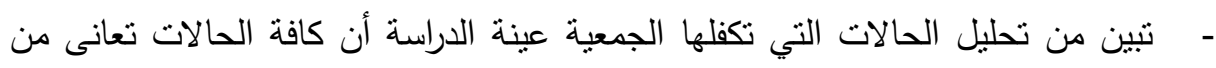

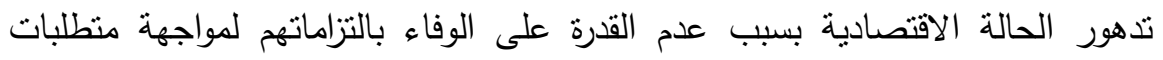

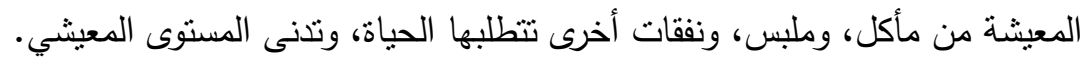


- البية الحالات التي تكفلها الجمعية بدون عمل ثابت ومستمر نظرا لظروفهم الاجتماعية والجسدية التي تمنعهم من العمل كالمرضى، والمسنين، والعاجزين، والمعيلات المسنات.

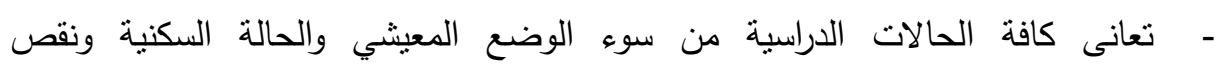
المستلزمات والأدوات المعيشة التي لا تكفى للحياة المعيشية. - بالنسبة للوضع البيئي لا يوجد بالمدينة التي تعيش فيها كافة الحالات الدراسية التابعة لكانة

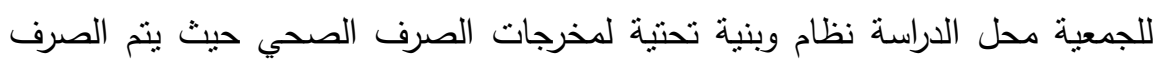

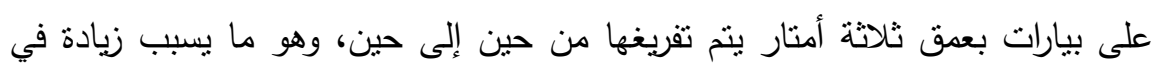

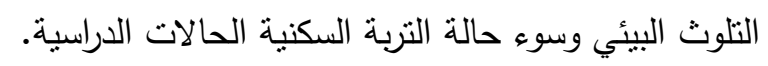

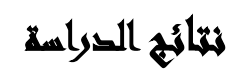

توصلت الدراسة إلى عدة نتائج منها الآتي:

هناك دور وجهود نطوعية تقدما الجمعيات التطوعية الخمس محل الدراسة من خلال

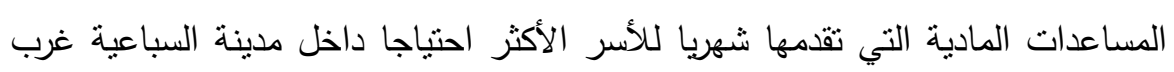

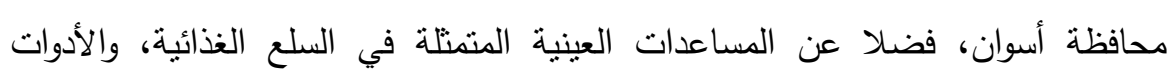
المنزلية، والأدوية، وتجهيزات ومستلزمات العرائس من الأسر غير القادرة.

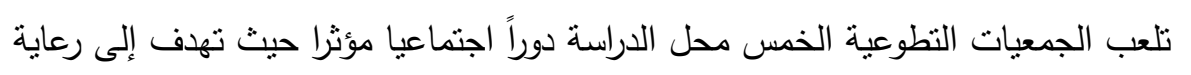
الأسر الأكثر احتياجا، ورفع مستواهم الثقافي والاجتماعي، والمساهمة في تحقيق مبدأ

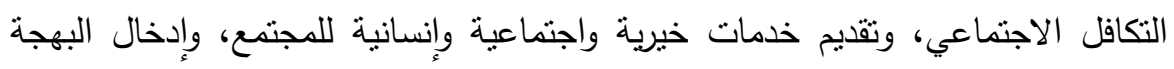

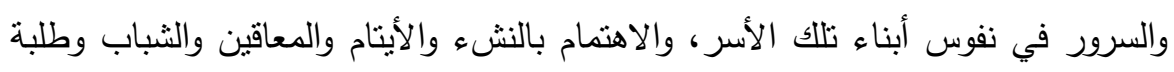
الجامعات. 
• تلعب الجمعيات التطوعية الخمس محل الدراسة دوراً اقتصاديا مؤثرا في رفع مستوى معيشة

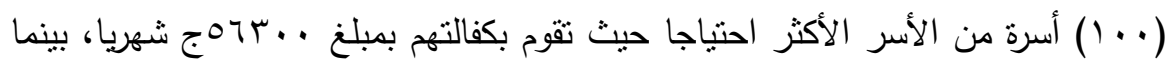

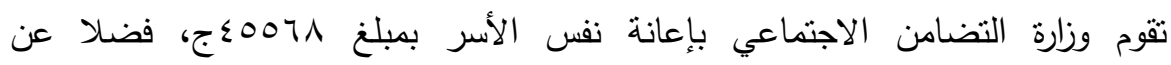

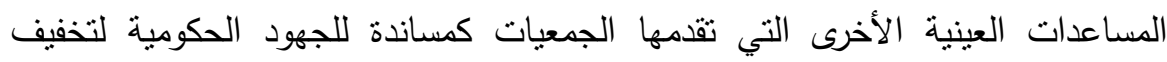
العبء عن نلاك الأسر. • تنين أن أهم المشكلات والصعوبات التي تواجه الأسر الأكثر احتياجا نتمتل في: تدنى الأى المستوى المعيشي والبيئي، تدهور الحالة الصحية، عدم كفاية الإعانات التكافلية الحكومية المقدمة، عدم وجود فرص عمل مناسبة للقادرين على العمل وخاصة السيدات المعيلات، كثرة الحالات شديدة المرض، كثرة حالات الأيتام الذين يعيشون بلا عائل.

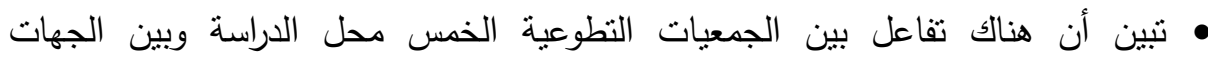
الحكومية للتسيق لعدم ازدواجية صرف الإعانات ومعرفة المنصرف لكل أسرة.

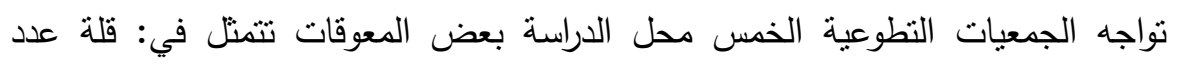

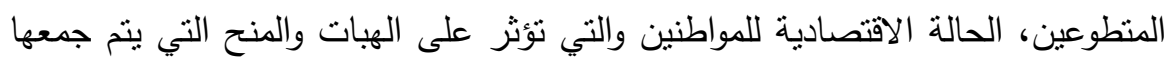
لإنفاقها على رعاية المحتاجين، عدم مناسبة المقرات التي تقطن بها إدارة الجمعيات.

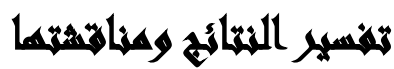

اتفقت نتائج الدراسة مع ما انتهت إليه بعض الدراسات المرتبطة من حيث الأهمية والأهداف: بالنسبة لمتغير الجهود التطوعية:

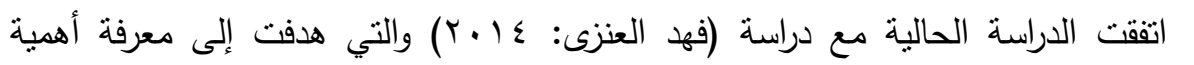
"الجهود التطوعية لمجلس حي النظم التطوعي ودورها في تحقيق الأمن والتتمية لسكان الحي"، وتوصلت نتائج الدراسة إلى أن هناك دور فعال للمنظمات التطوعية في رفع

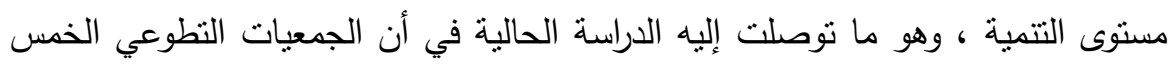

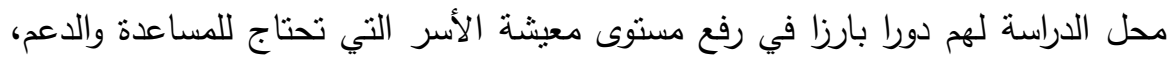
كما اتفقت الدراسة مع دراسة (محمد، صلاح: 10 أهمية "دور العمل التطوعي في تتمية المجتمع ونموذج مقترح لتفعيله"، وتوصلت الدراسة دراسة 
إلى تقديم نموذج لأهمية ودور العمل التطوعي لتتمية المجتمع، وهو ما توصلت إليه الدراسة الحالية في أنها أبرزت الجهود التطوعية ودورها داخل مدينة السباعية في مساعدة

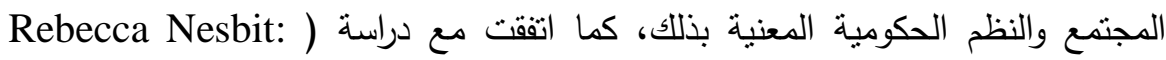
2017) والتي هدفت إلى التعرف على "أهمية التطوع داخل المنظمات ذات الصلة

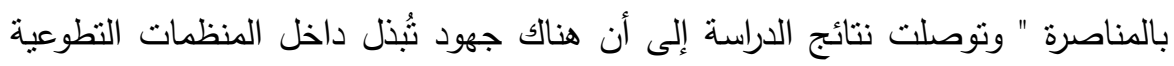
تساهم في تتمية المجتمع وتحقق منافع للمتطوع نفسه، وهو ما توصلت إليه الدراسة الحالية

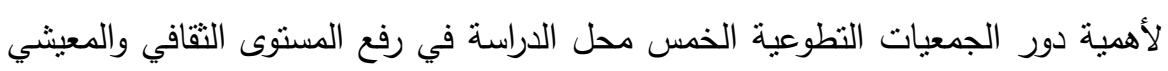
والاقتصادي للأسر الأكثر احتياجا داخل مدينة السباعية. بالنسبة لمتغير الأسر الأكثر احتباجا:

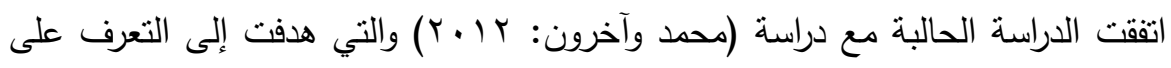
"سمات وخصائص الأسر الفقيرة في قطاع غزة" وتوصلت الدراسة إلى تقديم نموذج مقترح

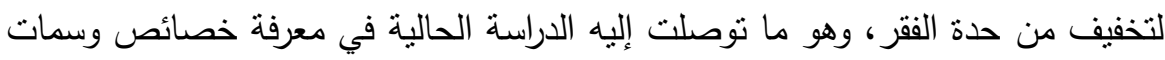

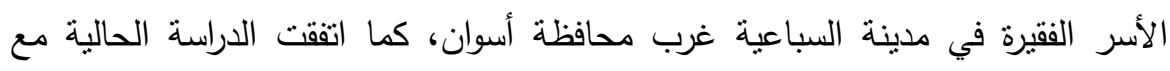
دراسة (Pawit M.: 2014) والتي هدفت إلى "البحث عن المعلومات الصحية بين الأسر الفقيرة في المناطق الريفية" وتوصلت نتائج الدراسة إلى تحديد حجم الأسر الفقيرة المحرومة البـ

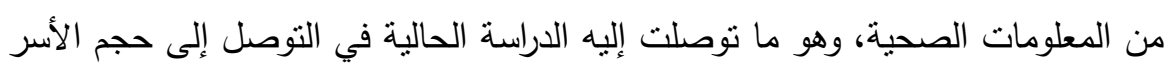
التي تعانى من مشكلات صحية، كما اتفقت الدراسة الحالية مع دراسة: (محمد عبد العال:

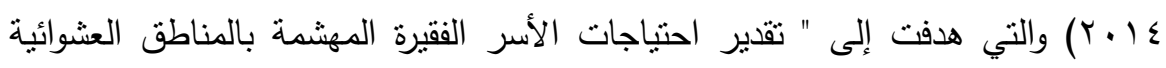
دراسة ميدانية مطبقة على الأسر الفقيرة بالمجتمعات العشوائية بالفيوم" وتوصلت نتائج

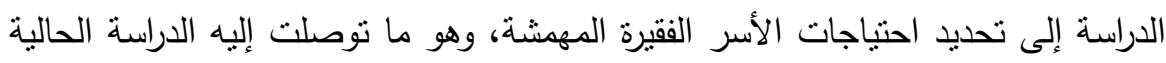
في تحديد الاحتياجات المادية والعينية للأسر الأكثر احتياجا بمدينة السباعية.

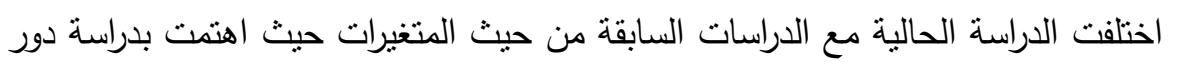
الجهود النطوعية وربطها بمتغير شدة الاحتباج متمثلا في الأسر الأكثر احتياجا داخل إحدى المدن المهمشة بمحافظة أسوان.

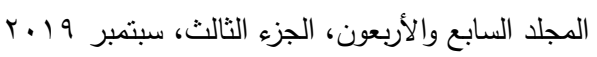


•اختلف الدراسة الحالية مع الدراسات السابقة من حيث التطبيق العملي حيث اهتمت

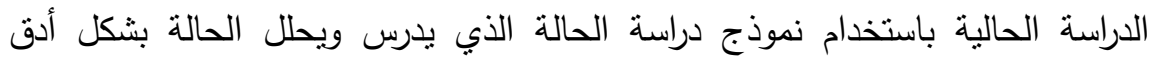
وأعمق لأنه يعتمد على المقابلة والملاحظة الثخصية التي تعطى نتائج مؤكدة.

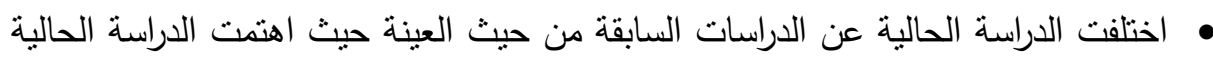

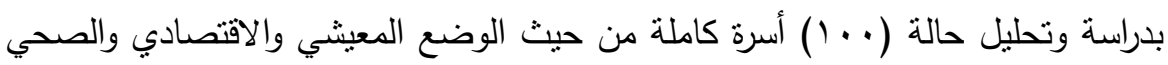
والبيئي.

\section{تروياهي التوراسة}

يوصى الباحثون بما يلي:

العمل على تضافر الجهود المجتمعية والاهتمام بالأسر الأكثر احتباجا وسد العجز الحكومي لضمان استمرار الحياة لتلك الأسر وتحسين مستوى معيثتهم. تبنى برامج وطرق بديلة للجمعيات التطوعية لاستمرار مساعدة الأسر المهشمة والأكثر احتياجا لضمان رعايتهم والعناية بهم. تذليل العقبات والقضاء على الروتين الحكومي في منح صلاحيات أكبر للجمعيات التطوعية للمساهمة في مساندة الحكومة في مساعدة الأسر غير القادرة على المعيشة.

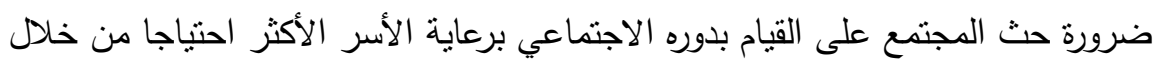
الإعلام وأماكن العبادة والجامعات والمدارس والثركات والمصانع للمساهمة في مساندة

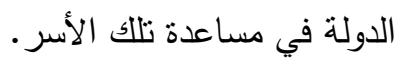

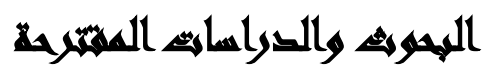

من خلا النتائج التي توصلت إليها الدراسة الحالية تقترح الباحثة مستقبلاً إجراء مزيد من الدراسات والبحوث في هذا المجال: • تقييم الوضع الاجتماعي والاقتصادي والبيئي للقرى المهشمة داخل مصر - دراسة تحليلية. • الآثار الاجتماعية للفقر على الأسر الأكثر احتباجا - دراسة تطبيقية. • التوافق النفسي والاجتماعي لأبناء الأسر الفقيرة وتأثنيره على البيئة المجتمعية. لإنية. 


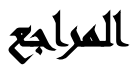

أحمد محمد السنهوري: الخدمة الاجتماعية في مجال الأسرة والطفولة، دار الحكمة للطباعة، وهاعة

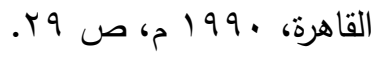

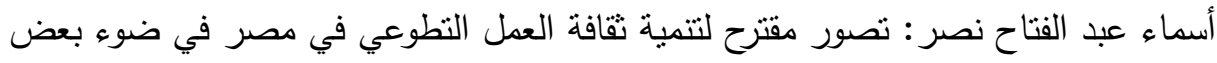

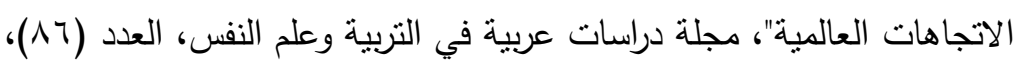

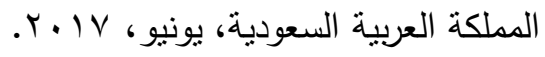
آمنة أحمد، مشاعل فهد: العمل التطوعي وقيم المواطنة لدى الثباب السعودي (دراسة ميدانية مطبقة على عينة من المنطوعين في المملكة العربية السعودية)، بحث مقدم إلى كلية الآداب، جامعة الملك سعود، السعودية، 10 ـ ب. الجهاز المركزي للتعبئة والإحصاء: إحصائية تعداد السكان، مركز المعلومات، القاهرة، . . IN

بلقاسم سلاطية، سامية حميدي: العنف والفقر في المجتمع الجزائري، دار الجزائر للطباعة،

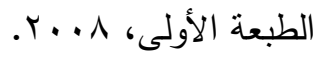

البنك الدولي: جعل الخدمات تعمل لصالح الفقراء، تقرير عن التتمية في العالم، ترجمة

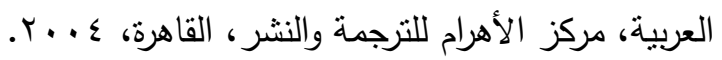

دية حنين: دور المؤسسات الخيرية في التتمية الاجتماعية مؤسسة الثيخ زايد للأعمال الخيرية والإنسانية نموذجا، رسالة ماجستير، كلية العلوم الاجتماعية والإنسانية، قسم لئه العلوم الإنسانية، جامعة الثهيد حمه لخضر - الوادي، الجزائر، 10 ـ بـ. رشاد أحمد عبد اللطيف: أساليب التخطيط للتتمية، المكنبة الجامعية، الإسكندرية، ؟ ... ؟. 


\section{رباب صبري أبو العلا وآخرون}

فاطمة محمد رفيدة: العمل التطوعي ودوره في تتمية المجتمع، رؤية واقعية لدور الجمعيات

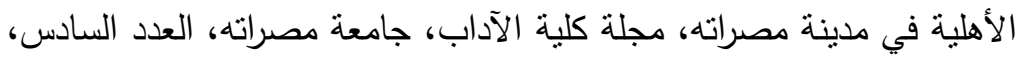

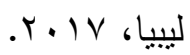

$$
\text { ليلى عبد الوهاب: منظمات المجتمع المدني، دار المنارة، القاهرة، هـ ـ. . . }
$$

موضي العنزي: أنزر بعض المتغيرات الاجتماعية والاقتصادية على مشاركة المرأة السعودية

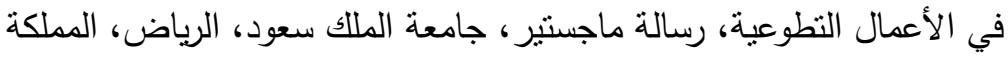

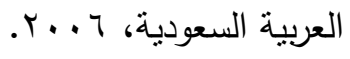

محد عبد العال عبد العزيز: تقدير احتباجات الأسر الفقيرة المهشمة بالمناطق العشوائية

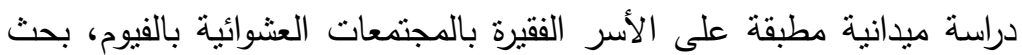

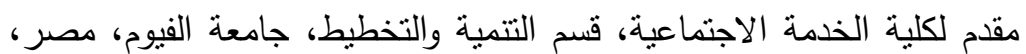

$$
. r \cdot 1 \varepsilon
$$

مازن محمد بركات: تحليل مجهري للفقر الريفي في محافظة الفيوم - دراسة حالة في قرية الجمهورية مركز طامية، مجلة كلية الزراعة، جامعة عين شمس، 10 ــr.

نجلاء فخر الدين رضا: مجالات الخدمة التطوعية في الجمعيات الخيرية النسائية، أبحاث

وأوراق عمل المؤتمر العلمي الأول للخدمات التطوعية بالمملكة العربية

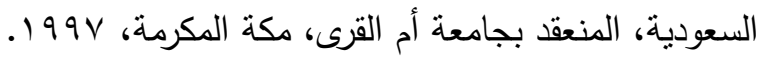

Chau-kiu Cheung and others (2015): Relationships Between Volunteerism and Social Responsibility in Young Volunteers, International journal Of Voluntary vol. (26), Issue (1).

Lili Wang and others (2017): An Empirical Examination of Formal and Informal Volunteering in Canada, International journal Of Voluntary vol. (28), Issue (1), February. 


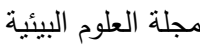

معهد الدراسات والبحوث البيئية - جامعة عين شمس لهس

Sintya Rosalina, et al (2018): Effect of Family Hope Program on Maternal Health Behavior and Children Under Five Nutritional Status in Poor Families, Jombang, East Java ,Journal of Maternal and Child Health 3(1).

\title{
THE ROLE OF VOLUNTARY EFFORTS IN IMPROVING THE SITUATION OF FAMILIES IN NEED - APPLIED STUDY ON THE CITY OF AL- SIBAIYA WEST OF ASWAN
}

\section{Rabab. S. Abou El-Eila(1); Mustafa E. Awad ${ }^{(2)}$ and Rashad A. Abdel Latif ${ }^{(3)}$}

1) Post-graduate student at Institute of Environmental Studies and Research, Ain Shams University 2) Institute of Environmental Studies and Research, Ain Shams University 3) Faculty of Social Work, Helwan University

\begin{abstract}
This study's purpose is to explore the reality and role of voluntary efforts of charitable associations in improving the situation of families most in need as the most prominent problems facing volunteering in rural, urban and marginalized communities that suffer from lack of interest in it, by applying to charitable associations Volunteering inside the city of Al- Sibaiya west of Aswan Governorate. And study the most-needed cases to ensure that these associations have an effective and effective role in improving the living of these families within the city, reviewing the material and in-kind assistance provided to them, (5)
\end{abstract}

$$
\text { المجلد السابع والأربعون، الجزء الثالث، سبتمبر } 9 \text {. }
$$


رباب صبري أبو العلا وآخرون

charitable associations aimed at social solidarity within the city are: Ahbab al-Khair Association, Al-Birr and Ihsan Society, Al-Ihsan Association, Kafalt Association Orphan, and finally Welfare Association (20) a case for each of the most needy families between, divorced women, breadwinners, widows, sick, orphans, incapacitated for work and poor, and the study relied on the inductive and deductive approach and the descriptive analytical approach to reach its goals, This approach was built on the combination of theoretical and applied study, and the theoretical framework was formed by compiling the scientific material on the subject matter of the study. 